\title{
ANALYSIS OF AVAILABILITY, QUALITY, AND PRICE OF FOOD OPTIONS IN DENVER, CO GROCERY STORES
}

\author{
A Thesis \\ Submitted to the Graduate Faculty \\ of the \\ North Dakota State University \\ of Agriculture and Applied Science
}

\author{
By \\ Jesse Adam Lunsford \\ In Partial Fulfillment of the Requirements \\ for the Degree of \\ MASTER OF SCIENCE \\ Major Department: \\ Health, Nutrition, and Exercise Sciences
}

October 2016

Fargo, North Dakota 


\section{North Dakota State University \\ Graduate School}

\section{ANALYSIS OF AVAILABILITY, QUALITY, AND PRICE OF FOOD OPTIONS IN DENVER, CO GROCERY STORES}

By

Jesse Adam Lunsford

The Supervisory Committee certifies that this disquisition complies with

North Dakota State University's regulations and meets the accepted standards for the degree of

MASTER OF SCIENCE

SUPERVISORY COMMITTEE:

Ardith R. Brunt, PhD, RD, Chair

Jerald Foote, $\mathrm{PhD}, \mathrm{RD}$

Yeong Rhee, $\mathrm{PhD}, \mathrm{RD}$

Mark Strand, PhD

Approved by Department Chair:

10-25-16

Date

Signature 


\begin{abstract}
In certain areas in the United States low-income, non-white populations have less access to healthy foods. This lack of access can manifest itself with higher costs, lower quality, or less availability of healthy food options. Research has shown a correlation between health status and ethnic and/or income status, which is related to negative correlations in health disparities and dietary intake. This study examined the Denver area grocery stores to identify if any populations had significant differences in food cost, food availability, or food quality. Thirty stores were randomly selected from Denver and analyzed using Nutritional Environmental Measure Survey for Supermarkets (NEMS-S). Results showed no significant relationships between cost, availability, or quality and socioeconomic status or minority status. Large supermarkets had better prices of healthier food options, and of higher quality than small, ethnic markets. Further research should assess behavioral decisions by consumers in Denver.
\end{abstract}




\section{ACKNOWLEDGEMENTS}

I would like to thank my committee for all of the time and effort that put into helping me through this process. Primarily Dr. Ardith Brunt, who was my primary advisor, for being a reliable point of contact. She was an excellent source of information and motivation. Without her guidance this project would not have been as successful as it was. I would like to thank Dr. Jerald Foote for helping me work through the study design and statistical analysis. Dr. Mark Strand and Dr. Yeong Rhee were the final parts of my committee that offered very valuable feedback throughout the process.

I would also like to note two of my undergraduate professors, Dr. Cynthia Dormer and Dr. Bruce Rengers. As I finished my internship, they both compelled me to consider graduate school. I appreciate them both investing the time in me. Without their "nudging" I'm not sure I would have ever applied to graduate school. They have provided constant motivation throughout my journey into dietetics.

Finally, I would like to thank my family. My wonderful wife, Courtney, has been supportive of me furthering my education every step of the way. Without her support at home I would not have been able to finish this process. She has provided mental and emotional support every single step of the way. My parents, Patricia and Evan, have always been supportive of me pursuing my goals. I'm thankful I had both of them to show their pride in my success, which helped take each step in my education. 


\section{TABLE OF CONTENTS}

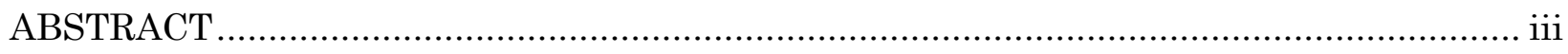

ACKNOWLEDGMENTS ..................................................................................

LIST OF TABLES ….........................................................................................

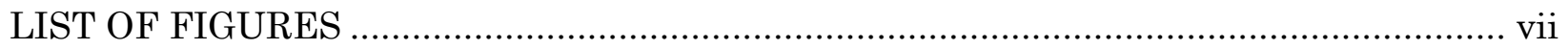

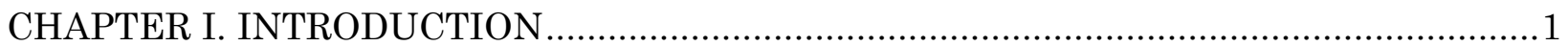

CHAPTER II. REVIEW OF LITERATURE..............................................................

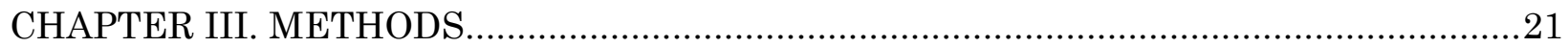

CHAPTER IV. ANALYSIS OF AVAILABILITY, QUALITY, AND PRICE OF FOOD

OPTIONS IN DENVER, CO GROCERY STORES ...................................................24

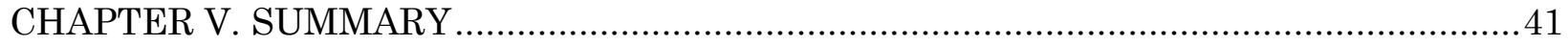

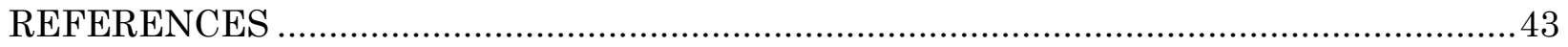

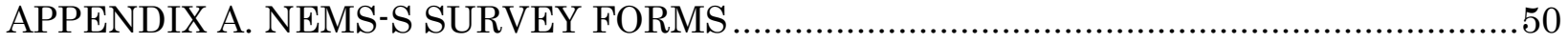




\section{LIST OF TABLES}

$\underline{\text { Table }}$

$\underline{\text { Page }}$

4.1. NEMS-S scoring systems for the different types of foods.

4.2. Store type, NEMS-S scores, and demographic information of the census tract area for the audited stores in Denver, CO. .35 


\section{LIST OF FIGURES}

$\underline{\text { Figure }}$

$\underline{\text { Page }}$

3.1. Map of the location of all the stores audited in Denver, CO .....................................22 


\section{CHAPTER I. INTRODUCTION}

Health disparities in the United States are a significant issue that researchers are trying to evaluate from a number of different directions. It is a very complex problem with many hypothesized causes. It is generally accepted that regardless of the ultimate cause, there is a clear disparity between socioeconomic groups (Fiscella \& Williams, 2004). It has been seen that lifespan, health outcomes, and overall health indicators are poorer in lower income people. There has been considerable time and money spent exploring some of the causes of this difference. Regardless of the cause, it is clear that those with lower levels of education, and therefore lower levels of income are less healthy than those who are educated and have higher income (Braveman, Cubbin, Egerter, Williams, \& Pamuk, 2010).

The benefits in dealing with health disparities are enormous for our society. One study estimated that if there were no health disparities for minorities, the total savings (over the 3 year period) would be approximately $\$ 1.2$ trillion (LaVeist, Gaskin, \& Richard, 2011). This savings is significant; therefore, resolving health disparities should be a priority. There are many socioeconomic reasons for health disparities that have been studied in depth. Access to health care, housing segregation, education levels, and income levels are just the beginning of the puzzle (Williams \& Collins, 2001).

\section{Organization of Thesis}

This thesis is presented in chapters. Chapter one is the introduction, which includes background, purposes and significance, research questions, limitations, and definitions. Chapter two is the review of literature on the topic. Chapter three discusses the methods for data collection and analysis. Chapter four is a research article that is ready for submission to a peer-reviewed journal. Chapter five is a summary of the research including future directions for on-going research. 


\section{Background}

Recently, more research has been done on preventative care and the impact it has on health disparities. There has been a shift in focus where more researchers are concerned about lifestyle choices preventing the need for excessive health care. People have become aware that some of the traditional areas that were blamed for health disparities (health care, access to care) were not the sole cause of health disparities (Woolf \& Braveman, 2011). This has prompted a further discussion of what is happening in those neighborhoods, including land use and community characteristics, and how that relates to further worsening the health disparities. This impact is compounded by the fact that there has been a link between poverty and obesity (Drewnowski \& Specter, 2004). Correlations have been seen between the highest rates of obesity populations which have the lowest education and the lowest income (Pampel, Krueger, \& Denney, 2010). The classical argument has been that cost is the problem in these environments (Darmon \& Drewnowski, 2015). This argument states that it costs far more money to eat in a healthy manner. There is some merit to this argument since foods that are calorie dense often are more affordable. This problem of calorie rich food often being less expensive shows itself in the diets of areas with higher poverty as they are consuming foods they can afford. The problem is further compounded by the fact that often the poor are working more hours and taking care of more children. They often have less free time to prepare meals, which leads them to select convenience foods. It has been seen that consumers with a lower food budget are more likely to choose foods high in fat, high in energy, low in fruits and vegetables and lean meats (Drewnowski \& Specter, 2004). This is a combination for potential nutrient deficiencies in the diet while consuming an excess of calories. It is easy to see that this combination can lead to further health problems. 


\section{Purpose and Significance}

While these studies have looked at a few different neighborhoods around the country, there has not been research done on the Denver Metro area. Denver has a large health disparity problem, where minorities are in significantly poorer health (Kincheloe, Palacio, Butler, Shupe, \& Ward-Hunt, 2013). Three out four American Indians, two out of three African Americans, and three out of five Hispanics in the Denver Metro area are overweight or obese. Only about half of the white Denver residents are overweight or obese (Kincheloe et al., 2013). The minority groups also have a lower average income (Current Population Survey, 2014). As seen earlier, there is a clear link between poverty and obesity, and Denver is no exception to that rule. This is even more prevalent in youth, since $15 \%$ of Hispanic high school students are obese, whereas only $5 \%$ of white high school students are. In every age bracket, white Denver residents have lower obesity and overweight rates than African American, Hispanic, or American Indian populations (Current Population Survey, 2014). It is a goal of Denver and the State of Colorado to reduce health disparities, and currently there are clear inequalities in Denver.

Identifying causes of health disparities can benefit society as a whole. There is considerable thought that the combination of food prices and diet quality in general can be a contributing factor to health disparities (Darmon \& Drewnowski, 2015). As noted previously we know that cost is not the entire issue. The purpose of this study was to evaluate the availability, cost, and quality of foods found in grocery stores in Denver, CO. We attempted to identify if there were any differences in stores based on local demographics. Furthermore, differences were evaluated between large, national grocery stores and small, non-national, local or ethnic markets. 


\section{Research Questions}

1. Do differences exist in price, quality, and availability of foods in Denver grocery stores?

2. If there are differences noted, what are the demographic characteristics of the neighborhoods those stores serve?

3. Are there any correlations between these differences and health status in these areas?

4. Are there differences between larger, national chain grocery stores and smaller, local, and ethnic markets?

\section{Limitations}

One of the limitations of this study is that we may not be able to make larger inferences for some of the population outside of Denver. The population in this study is Denver, and the stores are the treatments. Many of the stores bring independence into question as they may be supplied by the same distributor. In the sample there are many stores from the same chain since that is the most common option inside Denver. Despite the stores not having set pricing throughout the entire chain, it is hard to define the stores as independent. Furthermore, there are questions about pricing and availability being independent in competing stores. Pricing may be influenced by competitor's pricing and availability, so the entire market may lack independence. For the purpose of this study, the stores were necessarily dependent on each other, as the goal is to find differences between stores. Due to Denver being the population of this study, we can draw some conclusions concerning grocery stores in Denver, but are limited in using this information to describe other populations.

Another potential limitation of this study is that even though we are using the validated survey (Glanz, Sallis, Saelens, \& Frank, 2007), evaluating the quality of produce 
is subjective. This was addressed by training all of the dietetic student research assistants in an attempt to have everyone judge all foods in approximately the same manner. However, there is still subjectivity of each of the research assistants when evaluating quality of the produce listed on the survey. Furthermore, there is some inherent variability based on the fact that the people collecting the data may view foods differently at different stores. While the validated tool attempts to correct for this by giving clear guidelines for the analysis, there is still room for subjectivity.

Another possible limitation of this study is that there is going to be some natural variance when analyzing the stores. It is within reason that one particular day, a store was exceptionally busy, so it is not an actual representation of the mean availability of the store. To attempt to address this limitation NEMS-S survey suggests doing all data collection between 9:00AM and 4:00PM as stores are typically stocked at that time. Stores were audited more than once to minimize any potential anomaly. However, there is still potential for the data collected not being a true representation of the store.

With produce, there is a potential limitation based on seasons. Food availability changes throughout the calendar year as produce comes in and out of season. In order to address this potential limitation, all data was collected between April 1 ${ }^{\text {st }}$ and May 8th, 2016. This allowed stores to be checked multiple times in the same general time frame, and have consistent data from the same few weeks.

Finally, there is a limit to the sample size able to be assessed. Thirty stores were randomly selected in an attempt to evaluate most areas within Denver. While the selected areas have a variety of socioeconomic and ethnic characteristics, it is not a sample of the entire population. With limited resources, the 30 randomly selected grocery stores are used to attempt to best describe the target population and the differing characteristics between neighborhoods. 


\section{Definition of Terms}

Acceptable - Peak condition, top quality, good color, fresh, firm and clean (Glanz, Clawson, Davis, \& Green, 2015)

Availability - If a food is available at the time of audit (Glanz et al., 2015; "Nutrition Environment Measures Survey,").

Food Cost - The price of food per unit (noted in either per piece or per pound).

Food Quality - Defined as "Acceptable" or "Unacceptable", based on the majority $(>50 \%)$ of a particular type of produce. If it is hard to decide, the rater is instructed to mark "Unacceptable" and describe in comments (Glanz et al., 2015; "Nutrition Environment Measures Survey,").

Health Disparities -Inequality or difference, as in rank, amount or quality (Kindig, 2007). Also defined as health differences that adversely affect socially disadvantaged groups (Braveman et al., 2011).

Health Equity - Social justice in health. No person is denied the possibility to be healthy for belonging to a group that has historically been economically/socially disadvantaged (Braveman, 2014)

Health Inequity - Inequalities in health that are unfair, or come from some sort of injustice (Kindig, 2007)

NEM-S - Nutrition Environment Measures Survey - Supermarket. The validated survey that can be used to analyze cost, availability, and quality of foods (Glanz et al., 2007).

Poverty Income Ratio (PIR) - The income threshold defined by federal poverty levels based on family size. Expressed in percent of poverty level. 
Unacceptable - Bruised, old looking, mushy, dry, overripe, dark sunken spots in irregular patches or cracked or broken surfaces, signs of shriveling, mold or excessive softening (Glanz et al., 2015; "Nutrition Environment Measures Survey,"). 


\section{CHAPTER II. REVIEW OF LITERATURE}

\section{The Causes of Food Inequality}

Classical research has defined the major problem with food inequality as simply as stating that healthy food is more expensive than unhealthy foods. This argument states that energy dense food is typically less expensive (particularly per calorie) and for people on a limited budget, those foods end up being the logical thing to purchase (Drewnowski \& Specter, 2004). This conclusion is reached by looking at a few different factors. The first, and potentially most obvious link is that obesity rates are highest among those with the lowest incomes (and lowest levels of education) (Darmon \& Drewnowski, 2015). This is an interesting paradox, because people who have access to an excess amount of foods are not the most obese (Darmon \& Drewnowski, 2015). Since this is true, there must be something else at play because those with the least amount of potential access have the highest rates of becoming overweight. The simple answer is that the least expensive foods have the highest caloric values. There is an inverse relationship between the cost of a food and the calories that it contains. This means ultimately the individuals who have the least amount of money may end up choosing to purchase the foods that are the highest in calories. This problem occurs because the least expensive foods to produce are those that are high in fats and sugars (Drewnowski \& Eichelsdoerfer, 2010); therefore, these foods end up in the hands of individuals with the lowest income.

The root cause of this is more complex, because it starts with food assistance government programs. Those with the lowest incomes typically receive some type of food assistance, likely Supplemental Nutrition Assistance Program (SNAP). The USDA argues that the money allotted on SNAP is sufficient because every single person can eat a healthy diet on the allotted amount from SNAP (Hartline-Grafton \& Weill, 2012). The amount of 
SNAP dollars that someone receives is based on the "Thrifty Meal Plan" (TFP). This plan is designed in a way to allow a person to eat a healthy diet, and is the basis for determining the amount of SNAP dollars received. The ultimate problem with this plan is that it is created by an educated group of individuals who are able to formulate a healthy diet for the least amount of money. However, it neglects many other real concerns for people (Davis \& You, 2010). The TFP does not consider that many individuals who are receiving benefits are very busy and have very little time for food preparation. The TFP subsidizes people for food based entirely on the raw costs of the food. However, time is an integral part of any financial equation, and people simply do not have the available time in order to make the SNAP funding work. The TFP recommendations assumes that SNAP recipients are educated enough to shop in a thrifty manner and buy the right foods to stay under budget.

The other area the SNAP funding falls short is that the lowest cost healthy diets are not culturally appropriate for many of the cultures in the country (Maillot, Darmon, \& Drewnowski, 2010). A nutritious and affordable diet can be very bland with little variety. When the TFP was introduced, the designer paid very little attention to what types of foods that were affordable, just that nutritious foods were affordable (Davis \& You, 2010); (Hartline-Grafton \& Weill, 2012). This becomes even more problematic since most of the underserved and poor neighborhoods are of an ethnic background. Consumers typically will not ignore their culturally usual food just because they are told they can afford a healthy diet on the allotted funds. These factors lead to consumers in low income neighborhoods choosing between quick, unhealthy, socially acceptable options or options that are healthier, more time consuming, and may not respect their cultural norms.

More recently, analysis has grown beyond simply looking at the cost of food, to exploring what else strongly influences the food system. The obvious place to begin looking for further disparities in the food system would be at the grocery stores. In at least one 
study, wealthier white neighborhoods had far more produce options than lower income minority neighborhoods (Moore \& Diez Roux, 2006). This is problematic as we can begin to see that the disparities in the food system that are not just explained by cost. There are a number of reasonable explanations as to why the lower income stores would have less produce available. The most likely explanation is that if the cost is too high, then the demand would be too low for those neighborhoods. An alternative explanation could be that the grocers are catering to their population, and supplying foods they are accustomed to and will purchase. Whether it is due to cost or demand, this study supports the theory that lower income neighborhoods have less access to healthy foods, and therefore will be eating more high fat, high energy convenience foods.

The presence of a physical store is another factor that can change how someone chooses their foods (Ploeg, 2010). People are going to shop where they realistically can, and lower priced options are not always the realistic solution. Typically, smaller grocery stores are more expensive than supermarkets. Furthermore, the actual options available in these settings are more limited than their supermarket counterparts. Despite having more limited options, convenience foods are readily available in many of these settings. Many households without transportation may actually lack the choice of even shopping at a supermarket even if they wanted to. This concept is referred to as the "Grocery Gap", which explains the limited number of choices that individuals in low income neighborhoods have when finding fresh and affordable foods (Treufaht \& Karpyn, 2010). In 2009, 23.5 million Americans living in metro areas were found to be both low-income and not having access to a supermarket within one mile of their home. Furthermore, 9.7\% of all lowincome Americans did not have a supermarket within one mile of their home (Ploeg, 2010). Similarly, lower income neighborhoods have less total access to grocery stores and more access to convenience stores (Powell, Slater, Mirtcheva, Bao, \& Chaloupka, 2007). 
Having fewer grocery stores can have more reaching impacts than simply having fewer options of food. In lower income neighborhoods, there may be less produce in the stores they have access to, due to having fewer grocery stores in the neighborhood. This is a serious problem because people in low income neighborhoods often have other hurdles to grocery shopping, such as limited childcare or transportation. In fact, simply having poor perceived access to a grocery store can make someone have less desirable dietary choices (Caspi, Kawachi, Subramanian, Adamkiewicz, \& Sorensen, 2012). In this study, people chose more fruits and vegetables if they believed that they could walk to a grocery store. There was a strong correlation between perceived access to the store and fruit and vegetable intake. This means that regardless of how close the store physically was, if the resident felt it was inaccessible it changed food behaviors. The participants of this study were not in a food desert, yet still had limited perceived access. In areas with fewer grocery stores, people will necessarily be further from the store on average. If they perceive this distance to be too great, they will make poorer dietary choices. Combined with the fact that when they actually get to the store, they have on average worse choices available, it is clear that this problem is more complex than just the cost of the foods.

The general public has consistently said they are concerned with the cost of food, the quality of food, the location of stores, and the quality of the stores when making food choices (Evans et al., 2015). These study participants defined a store as high quality when it was clean, in good physical condition, and did not have panhandlers in the parking lot. Often, stores in lower income neighborhoods are of worse quality. There are not always these differences in grocery store environments. In Hartford, CT, researchers found that there were not significant differences in price or availability; however, food quality and store quality were worse in low income areas (Martin et al., 2014). 
The delivery of food to the general public is more complex than simply the price. As seen there are a myriad of factors which can cause lower income neighborhoods to have more challenges with acquiring healthy food. This makes the issue complex and as a result, we cannot simply have an intervention to make produce cost the same in all neighborhoods. Disparities in the food system are a multi-faceted problem where inequalities can take many forms.

\section{Health Disparities and Health Inequity}

Health disparities are defined as health "inequality or difference, as in rank, amount, or quality" (Kindig, 2007). Simply stated, there should not be health differences among different demographical areas. If we were to see different health outcomes for areas of lower-income or different racial or ethnic backgrounds, there would be a cause for concern and something we would ideally want to address. Health inequity is more concerned with whether or not something is fair or just (Kindig, 2007). This is a small, but important distinction that is worth considering when evaluating this issue. It is possible that there is a disparity, but not an inequity, based on the concept of justice. It is worth keeping in mind the concept of justice, as there may be outside factors causing these health disparities.

There is nothing about being non`white that necessarily requires one to be of poorer health status in the United States. Our current system does indicate that people will be less healthy based on their income status, but that is a potentially avoidable piece that society could work through for health equality (Braveman et al., 2011). This can be due to religion, race, economic standing, social standing, or some other characteristic that results in health inequality. Health inequities are typically due to systemic issues, which make them potentially solvable. There is an inherent social disadvantage for many that are poor, and these people are often over-represented as non-white. It is important to note that for 
health inequities to exist, it is not necessary that an entire population will be

disadvantaged. Not all poor people are going to develop diabetes, not all lower-income nonwhite residents will end up obese, and not all people from an at-risk community will develop disease. A lack of doctors, supermarkets, clinics, transportation, or health facilities in a neighborhood can create a disparity even if not all members result in having negative health outcomes. When those with social advantage experience, on average, better health outcomes we are faced with health inequality.

One classic example of this is that black populations have much lower birth weight babies on average (Child Health USA 2013, 2013). This results in more premature births, higher infant mortality, and slowed cognitive development (Braveman et al., 2011). This is a sign of a health disparity because there is nothing in the population that would suggest that those children should inherently and necessarily be born at a low weight. Not all health differences are examples of health disparities. Those who ride motorcycles being more at risk than those who do not is not an example of a health disparity. There is something inherent and necessary that indicates those engaging in that activity are more at risk for harm. Populations can have health differences without it being an example of a health disparity. There is a necessary social injustice that relates to health disparities. It is important to define health disparities and inequities appropriately so we can evaluate if it is due to injustice that a population is facing poorer health outcomes. If there are differences in health outcomes for lower-income, non-white populations this is an example of a health disparity. This is also the focus of this research.

\section{Link between Nutrition and Health Inequities}

Recent research has shown that there is a link between access to healthy foods one can afford and potential health problems (Ploeg, 2010). While this is a complex issue with 
many factors throughout the entire health care system, we can continually see that a lack of access to healthy foods correlates to poorer health status in a population.

It starts to become a health inequities issue as this lack of a variety of foods is normally characterized by neighborhoods that are classified as low-income, communities of color, and rural (Treufaht \& Karpyn, 2010). This is an important piece when considering the health inequities since there are links between higher Body Mass Indices (BMIs) and access to healthy foods (Rose, 2010). This becomes an issue of health equality since access to food is the biggest challenge for people who live in low income neighborhoods, often communities of color, and rural areas (Treufaht \& Karpyn, 2010).

One major meta-analysis evaluated 31 studies about food deserts as they relate to racial/ethnic characteristics and income disparities (Walker, Keane, \& Burke, 2010). Their findings showed that more or less across the board, there were systemic problems which led to specific populations being under-served with food delivery. The lowest income areas in the country have fewer supermarkets available than the highest income neighborhoods (Walker et al, 2010). As discussed earlier, supermarkets offer the best prices and the best availability means that those smaller stores in the lower-income areas have fewer options with higher prices. Furthermore, even when there are supermarkets close by, neighborhoods of color typically have less availability in the supermarket than white neighborhoods, often offering only half as many choices (Powell et al., 2007). In addition to having fewer actual stores in these poor neighborhoods, the quality of the food in the stores often suffers as well. A recent study within areas of Minnesota found that much of the produce in the areas with highest poverty levels was of poor quality, and often not even edible (Hendrickson, Smith, \& Eikenberry, 2006). According to the study, residents of these areas felt that their ability to eat healthy was being impacted by the lack of options in their environment. 
The next step in the link between nutrition and health inequities is that health status actually improves with access to healthier foods. It has been seen that residents of neighborhoods with better access to healthy, fresh foods have lower BMI, lower levels of obesity, and overall healthier diets (Larson, Story, \& Nelson, 2009). In fact, in some neighborhoods, there is a clear distinction in BMI between areas with supermarkets and areas with only convenience stores (Morland, Diez Roux, \& Wing, 2006). Residents who lived in an area with a supermarket had a $9 \%$ lower prevalence of obesity than those who did not. Those who lived in an area with primarily convenience stores had a higher risk of being overweight, being obese, and suffering from hypertension. Quite simply, people who did not have access to supermarkets had a higher prevalence of being overweight and obese (Morland, et al, 2006). This lack of access is disproportionately found in non-white, lowincome neighborhoods; therefore, the lack of nutritious options is contributing in health disparities in the U.S.

Furthering the health inequality in these areas, studies show that foods required to manage disease states are not often available in areas without supermarkets (Horowitz, Colson, Hebert, \& Lancaster, 2004). This study assessed supermarkets available to people managing diabetes in East Harlem and Upper East Side New York. Horowitz and colleagues (2004) found significant differences in the stores in poorer areas (Harlem) compared to stores in the wealthier areas (Upper East Side). In fact, less than $20 \%$ of the stores in East Harlem even carried the foods that were recommended in managing the diabetic diet. Since obesity is a risk factor for diabetes, this as an example to see how the health inequality become a problem these neighborhoods (Pi-Sunyer, 2002). Simply put, people in these lower-income neighborhoods become more at risk for developing certain nutrition related diseases and then are less equipped to manage the diseases because of their environments. 
In addition to obesity and obesity related diseases, a number of other conditions can become problematic in lower-income neighborhoods. Because produce is of lower quality, more expensive, and less available, there are often vitamin deficiencies that can cause health problems for individuals in these neighborhoods (Seligman, Laraia, \& Kushel, 2010). The National Health and Nutrition Examination Survey (NHANES) reported that many people in food insecure areas are more at risk for many health complications due to dietary intake (Seligman et al., 2010). Additionally, due to the lack of fresh produce, they often consume below recommended levels of fruits, vegetables, and dairy resulting in lower levels of vitamins and minerals (Seligman et al., 2010).

Iron deficiency anemia is a preventable condition that results in reduced growth and poorer cognitive development in children (Abu-Ouf \& Jan, 2015). Pregnancy places additional iron needs on the body, and many women never reach the recommended iron intake through pregnancy. Iron deficiency can result in stunted growth both in the fetus and in the child, in addition to stunted social and cognitive function. Children who are food secure are far less likely to actually have iron deficiency anemia (Skalicky et al., 2006). As iron deficiency anemia is a public health focus, and lower-income rural residents are more likely to suffer from iron deficiency anemia, we can continue to see the health inequities created by food security and the food delivery system.

Ultimately, what we see is that under-served areas (low-income, typically neighborhoods of color) have less access to fresh foods, and the access comes at a higher cost. These areas have a higher level of chronic diseases that can be managed with nutrition (hypertension, diabetes). When people attempt to manage these diseases appropriately, they have even less options for the recommended foods for medical nutrition therapy. The demographics of these areas are preventable, unjust, unnecessary, and not 
equal. It becomes clear there are actual health disparities in these lower-income neighborhoods and access to healthful foods may be part of it.

\section{Nutrition Environment Measures Survey in Stores}

The tool used for the analysis of the grocery stores is the Nutrition Environment Measures Survey in Stores (NEMS-S). NEMS-S is a validated survey that allows one to evaluate the availability, quality, and price of healthy foods in stores (Glanz et al., 2007). Glanz and colleagues found that the NEMS-S survey has a high level of reliability and can be used to show significant differences across different stores. This makes it an appropriate and validated tool to analyze grocery stores in this study. A maximum total score was 54, which consisted of a maximum of 30 for availability, 18 for cost, and 6 for quality of produce (Glanz et al., 2007). Scores were based on whether or not food was available, the cost difference between healthier and usual options, and the overall quality of produce.

Availability scores were calculated based on the total number of healthier options available. For milk, stores earned 2 points if they have low-fat/skim milk, and an additional point if they had a $>50 \%$ ratio of lowest-fat to whole. For fruits and vegetables, they earned points based on the varieties available (out of 10). If they had 0 varieties they would earn 0 points, $<5$ varieties was worth 1 point, 5-9 varieties was worth 2 points, and all 10 varieties was worth 3 points. Ground beef earned 2 points if they had $90 \%$ lean meat (or leaner), 1 additional point if they had 2-3 varieties of lean meat, and 2 additional points if they had $>3$ varieties. Hot dogs earned 2 points if they had fat free, or 1 point if they had light, but not fat-free hot dogs. Frozen dinners earned 3 points if they had 3 different options, or 2 points if they had 1 or 2 options. Baked goods earned 2 points if they had lowfat items. If a store had diet soda or $100 \%$ juice they would earn 1 point for each option of beverage. A store offering whole grain bread would earn 2 points, and if they had $>2$ varieties of whole wheat bread they would earn an additional point. If a store had baked 
chips they would earn 2 points, and an additional point if they had $>2$ varieties of baked chips. Finally, if they offered a cereal with $<7$ g sugar per serving they would earn 2 points. Cost was calculated based on comparison between healthier and less healthy options. For milk, if lowest fat milk was less expensive than whole the store was awarded 2 points, if it was the same cost they were awarded 1 point, and if whole milk was less expensive they were awarded -1 . For all other foods mentioned previously, if the healthier option was more expensive a store received a score of -1 . If the healthier option was less expensive, they received a score of 2 . Fruit and vegetables are not used in the cost calculation since there are not healthier options for fruits and vegetables.

Quality measured only fresh fruits and vegetables, and it was based on the percent of options that were acceptable. If $25-49 \%$ were acceptable the store received 1 point. $50^{-}$ $74 \%$ acceptable the store was awarded 2 points, and if $75 \%$ or greater was acceptable the store was awarded 3 points. Scoring was done for fruits and vegetables separately, to a maximum of 6 total points.

The NEMS-S tool evaluates 12 different measures (milk, fruit, vegetables, canned items, hot dogs, beverages, water, baked goods, bread, chips/snacks, cereal, and miscellaneous). This affords the opportunity to look at the price, quality, and availability of foods at each of the different stores. The NEMS-S tool has an online application that allows data to be collected in a simple manner, called Store Audit Center (SAC). SAC was the primary method in which data is recorded. This allows the researcher to upload all the data from a smart phone and get reports printed directly from the SAC website. This was very valuable for both ease of data collection and data analysis.

All types of surveyed foods are evaluated on the availability of the foods. If the food is available it is noted, and if the food is not available it is noted. Quality is only evaluated on fresh fruits and vegetables. Foods are either "acceptable" or "unacceptable". 
Unacceptable foods are any produce that are "bruised, old looking, mushy, dry, overripe, dark sunken spots in irregular patches or cracked or broken surfaces, signs of shriveling, mold or excessive softening" (Glanz et al., 2015; "Nutrition Environment Measures

Survey,"). If a surveyor is unsure if the food is acceptable or unacceptable, it is to be marked unacceptable. This is done to reduce the amount of subjectivity in the analysis. Price is analyzed as absolute price for fruits and vegetables. The total cost of the fruit or vegetable was collected in either per unit or per pound measurements. Comparative cost is used for the rest of the sections as each of the foods has standard options and healthier options. The healthier to regular comparisons are:

1. Skim milk vs whole milk

2. Lean ground beef ( $90 \%$ lean/10\% fat) vs regular ground beef ( $80 \%$ lean/20\% fat)

3. Low-fat hot dogs vs regular hot dogs

4. Reduced calorie frozen dinner vs regular frozen dinner

5. Diet/low calorie soda vs regular soda

6. $100 \%$ fruit juice vs juice drinks

7. Lower fat baked goods vs regular baked goods

8. $100 \%$ whole grain bread vs refined grain bread

9. Baked/low-fat snack chips vs regular snack chips

10. Cereals with $<7$ g sugar vs regular cereal

These comparisons are done in order to gather data regarding all the food options that a consumer has available. The goal is to determine if there are significant differences in "healthier" options within a store, as well as between different areas. The NEMS-S tools give a complete picture of pricing, quality, and availability for a given store.

The NEMS-S guidelines suggest completing the assessments between $9 \mathrm{am}-4 \mathrm{pm}$ each day. Generally during those times, the store has already been stocked, and has not already 
been sold out. Doing the audits during this timeframe gives the highest level of reliability for this measurement tool. The NEMS-S creators also state that all pricing must be evaluated at a usual price, if possible. Looking at the price for a sale item skews the data and not give an accurate representation of the usual cost of an item. It is important to try to get as usual of a picture at a particular store as possible to increase reliability. The preferred option is the store brand at each particular store, according to NEMS-S. A good example is milk, which can often have a wide range of prices for a similar product. Looking at the store brand gives a good baseline at each particular location. Furthermore, in times when the same chain of store cannot be found in the area, the store brand gives an acceptable starting point for a picture of the overall prices. NEMS-S is a highly reliable survey and applicable to different geographic areas (Glanz et al., 2007). It was reliable to test the environments in different geographical areas, as well as different types of stores.

\section{Summary}

Disparities and inequities in the food system are a multi-faceted problem which cannot be solved with a simple intervention of making cost equal at all stores. As noted, there have been observed disparities in cost, quality, and availability between different locations of grocery stores. NEMS-S attempts to evaluate these inequities in the food system, and was used to analyze the selected stores. 


\section{CHAPTER III. METHODS}

The purpose of this study is to determine if there are differences in grocery store availability, pricing, and quality in the Denver Metro area. This study analyzed 30 stores randomly selected from the Denver Metro area.

\section{Selection of Stores}

A list of stores was obtained through the City of Denver Health Department which included all stores they have tagged as "grocery stores" in the city. There were 347 stores listed. Every store on the list was evaluated and excluded from the randomization based on one of four factors:

1. The store was now closed (verified by calling them).

2. The store was a convenience store or gas station (verified by calling and evaluating if they have a produce section).

3. The store was not a food store at all (verified by calling and asking if they sell food).

4. The store served primarily ready to eat foods.

Out of the 108 remaining stores, 30 grocery stores were randomly selected. A sample size of 30 stores was used due to the available resources for data collection. With a full population of 108 stores, a sample size of 30 stores at a confidence level of .95 returns a margin of error of $15.3 \%$. After data collection began, two of the selected stores were found to be either closed or duplicates; therefore, two additional randomly selected stores from the list were added after audits began. The first, Mi Pueblo Latin Market, was found to be closed once the first auditor arrived. The second, Little Saigon Market, was found to be the same store as Far East Oriental Market. Figure 3.1 shows the location of all audited stores. 


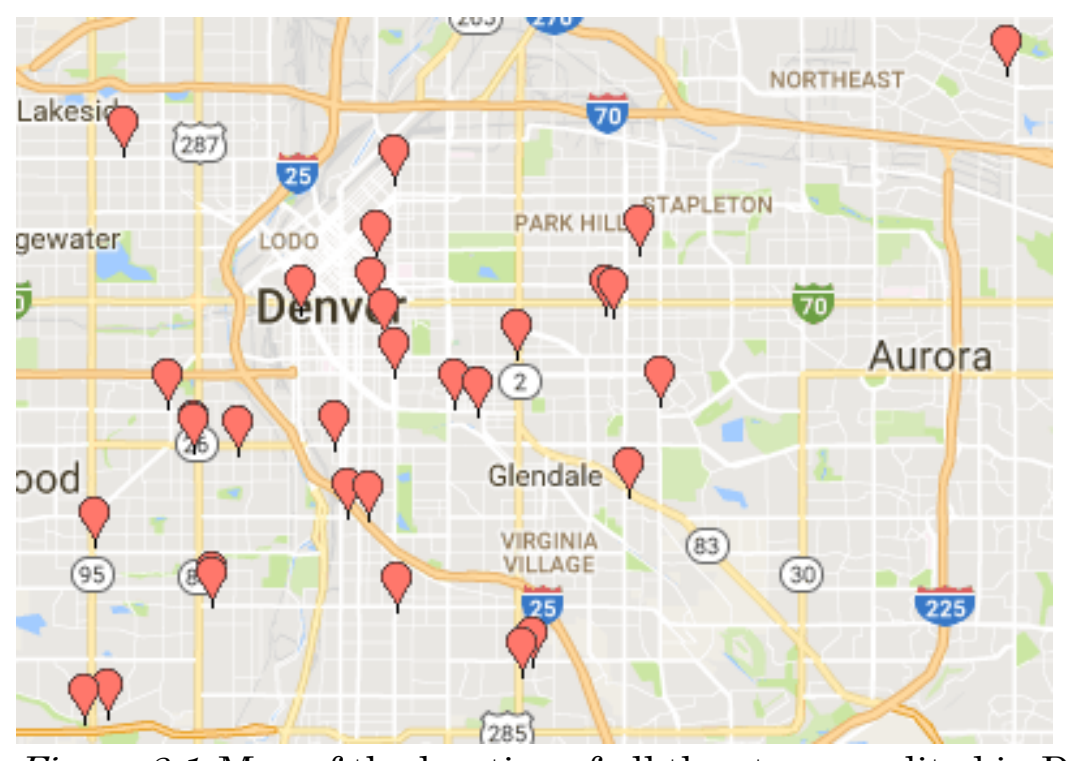

Figure 3.1. Map of the location of all the stores audited in Denver, CO

\section{Study Design}

This study is an observational cross-sectional study of grocery store quality within the Denver Metro area. The selected stores were audited using the NEMS-S tool to evaluate availability, price, and quality of the selected food items in those locations. Seven undergraduate students and alumni were recruited from the Denver Metropolitan State University's Human Nutrition-Dietetics program to assist with data collection. All surveyors completed the NEMS-S online training prior to conducting store audits. All data were collected between April $1^{\text {st }}$ and May $8^{\text {th }}, 2016$ between the hours of 9:00AM and 4:00PM.

Data were averaged across all individual audits for respective stores. This researcher audited all 30 stores one time, and randomized the 30 stores among the seven research assistants. Each store was assigned to two different assistants (for a total maximum of three audits of each store). The assistants were blinded to the purpose of the study, to each other, to store demographic data, and to the total number of stores audited. The only information they were given was the due date to complete their audits and the addresses of their assigned stores. Most research assistants used the online application 
through Store Audit Center and were able to input the information directly as they audited. For those who opted to use the paper audit forms, data were inputted from paper audit forms into the Store Audit Center.

\section{Statistical Analysis}

Each store was defined with a total NEMS-S score, as well as sub-scores for availability, cost, and quality.

Census data were gathered for the census tract where each store was located. Demographic data that were evaluated included percent White residents, total household income, percent of residents in poverty, and family size. Poverty Income Ratio (PIR) was also calculated. Federal guidelines for poverty were used and adjusted based on family size. Store type was identified as "national chain" or "non-national chain". The nonnational chain group included small neighborhood and ethnic markets.

Kruskal-Wallis was used to compare availability, because the distribution was not normal. ANOVA compared cost and quality. Percent poverty income ratio, percent white resident (based on quintiles), percent residents in poverty, and "national chain" vs "nonnational chain" were all tested for all three variables of availability, cost, and quality. Cost and quality were calculated using Analysis of Variance. IBM SPSS Statistics 23 was used for all testing (IBM Corp. Released 2013. IBM SPSS Statistics for Windows, Version 22.0. Armonk, NY: IBM Corp.). 


\title{
CHAPTER IV. ANALYSIS OF AVAILABILITY, QUALITY, AND PRICE OF FOOD OPTIONS IN DENVER, CO GROCERY STORES
}

\begin{abstract}
In certain areas in the United States low-income, non-white populations have less access to healthy foods. This lack of access can manifest itself with higher costs, lower quality, or less availability of healthy food. Research has shown a correlation between health status and ethnic and/or income status, which is related to negative correlations in health disparities and dietary intake. This study examined the Denver area grocery stores to identify if any populations had significant differences in food cost, food availability, or food quality. Thirty stores were randomly selected and analyzed using Nutritional Environmental Measure Survey for Supermarkets (NEMS-S). Results showed that there was no significant relationship between cost, availability, or quality and socioeconomic status or minority status. Large supermarkets had better prices of healthier food options, and of higher quality than small, ethnic markets. Further research should assess how consumers make store decisions and consequent purchasing decisions.

\section{Introduction}

\section{Background}

Health disparities in the United States are a significant issue that researchers are trying to evaluate from a number of different directions. It is a very complex problem with many hypothesized causes. It is generally accepted that regardless of the ultimate cause, there is a clear disparity between socioeconomic groups (Fiscella \& Williams, 2004). Lifespan, health outcomes, and overall health indicators are poorer in lower income people. There has been considerable time and money spent exploring some of the causes of this difference. Regardless of the cause, it is clear that those with lower levels of education, and 
therefore lower levels of income are less healthy than those who are educated and have higher income (Braveman et al., 2010).

Recent research has shown that there is a link between access to healthy foods one can afford and potential health problems (Ploeg, 2010). While this is a complex issue with many factors throughout the entire health care system, we see that a lack of access to healthy foods correlates to poorer health status in a population. It then becomes a health disparity issue as this lack of healthy foods is normally characterized by neighborhoods that are classified as low-income, communities of color, and rural (Treufaht \& Karpyn, 2010). Furthermore, there have been observed negative correlations between higher Body Mass Indices (BMIs) and access to healthy foods (Rose, 2010). This becomes an issue of health equality since access to food is the biggest challenge for people who live in low income neighborhoods, often communities of color, and rural areas (Treufaht \& Karpyn, 2010).

Researchers have shown links between poverty and obesity, identifying that those in poverty are more likely to be obese (Drewnowski \& Specter, 2004). Historically the areas that had the highest rates of obesity had the lowest levels of education and lowest incomes. The classical argument has been that cost of healthy food is the problem in these environments (Darmon \& Drewnowski, 2015). This argument basically states that it costs far more money to eat in a healthy manner. There is some merit to this argument since foods that are calorie dense often are more affordable (Darmon \& Drewnowski, 2015). This problem of calorie rich food often being less expensive per calorie can lead to poorer health outcomes in areas with higher poverty since people in these neighborhoods are consuming foods they can afford (Drewnowski \& Eichelsdoerfer, 2010). The problem is further compounded by the fact that often the poor are working more hours and taking care of more children. Time is an integral part of any financial equation, and people with lower income simply do not have the available time to prepare food from scratch, which leads them to 
select convenience foods. This leads to consumers with lower food budgets to choose foods that are high in fat, energy, and low in fruits, vegetables, and lean meats (Drewnowski \& Specter, 2004). Additionally, due to the lack of fresh produce, they often consume fruits, vegetables, and dairy below recommended levels resulting in potentially being deficient in vitamins and minerals (Seligman et al., 2010). The reason these foods are the cheapest is it is cheaper to produce foods that are high in fat and sugar (Drewnowski \& Eichelsdoerfer, 2010). Moreover, these foods are shelf stable and do not spoil as quickly as more nutrient dense produce might.

Research has shifted from looking simply beyond just the cost of foods, and is starting to analyze the food system as a whole. Lower income neighborhoods have less total access to grocery stores and more access to convenience stores (Powell et al., 2007). Grocery store access can be an important piece, since convenience stores typically offer less produce and healthier options. This is a serious problem because people in low income neighborhoods often have other hurdles to grocery shopping, such as longer working hours, limited childcare or transportation. Often, people simply shop at the store closest to them (Fiechtner et al., 2016). This means that if they don't have a grocery store close, they may shop instead at convenience stores. In fact, simply having poor perceived access to a grocery store can make someone make less desirable dietary choices (Caspi et al., 2012). Caspi and colleagues found people chose more fruits and vegetables if they believed that they could walk to a grocery store. There was a strong positive correlation between perceived access to the store and fruit and vegetable intake. This means that regardless of how close the store physically was, if the resident felt it was inaccessible it changed food behaviors. The participants of this study were not in a food desert, yet still had limited perceived access. In areas with fewer grocery stores, people will necessarily be further from the store on average. If they perceive this distance to be too great, they will make poorer 
dietary choices. Combined with the fact that when they actually get to the store, they have on average worse choices available, it is clear that this problem is more complex than just the cost of the foods.

In addition to having fewer actual stores in these low income neighborhoods, the quality of the food in the stores often suffers as well. A recent study within areas of Minnesota found that much of the produce in the areas with highest poverty levels was of poor quality, and often not even edible (Hendrickson et al., 2006). According to the study, residents of these areas felt that their ability to eat healthy was being impacted by the lack of options in their environment. This shows that even if a grocery store is close enough to shop in, stores in high poverty neighborhoods may still lack acceptable options when compared to wealthier neighborhoods.

This becomes a health inequity issue because residents of neighborhoods with better access to healthy, fresh food have lower Body Mass Index (BMI), lower levels of obesity, and overall healthier diets (Larson et al., 2009). In some neighborhoods, there is a clear distinction in BMI between areas with supermarkets and areas with only convenience stores (Morland et al., 2006). Residents who lived in an area with a supermarket had a 9\% lower prevalence of obesity than those who did not. Those who lived in an area with primarily convenience stores had a higher risk of being overweight, being obese, and suffering from hypertension. This lack of access is disproportionately found in non-white, low-income neighborhoods; therefore, the lack of nutritious food choices is contributing in health disparities in the U.S.

Nutritional management of chronic disease can be impacted in lower-income areas as well. Recommended foods for disease management are less available in low-income areas (Horowitz et al., 2004). Horowitz and colleagues found significant differences in the stores in low-income areas (East Harlem, NY) compared to the stores in wealthier areas 
(Upper East Side, NY). Less than $20 \%$ of the stores in East Harlem carried the foods that were recommended in managing the diabetic diet. As obesity is a risk factor for developing diabetes, one can begin to see how health inequality can occur specifically in these areas (Pi-Sunyer, 2002). As residents have access to less produce they may also experience vitamin deficiencies, which can lead to further chronic diseases (Seligman et al., 2010).

\section{Nutrition Environment Measures Survey in Stores}

The tool used for the analysis of the grocery stores was the Nutrition Environment Measures Survey in Stores (NEMS-S). NEMS-S is a validated survey that allows one to evaluate the availability, quality, and price of healthy foods in stores (Glanz et al., 2007). Glanz and colleagues found that the NEMS-S survey has a high level of reliability which can be used to show significant differences across different stores. This makes it an appropriate and validated tool to analyze grocery stores in this study. Scores were based on whether or not food was available, the cost difference between healthier and less nutrition dense options, and the overall quality of produce.

The purpose of this study was to evaluate the availability, cost, and quality of foods found in grocery stores in Denver, CO. We determined if there were any differences in stores based on local demographics from census tract data. Furthermore, differences were evaluated between large, national grocery stores and small, non-national, local or ethnic markets.

\section{Methods}

Stores were selected from a list of stores that were inspected by the Denver Department of Health. Stores were excluded only if they were no longer open, if the store did not sell food, if they primarily served ready to eat foods, or self-identified as a convenience store or gas station without a full produce section. From the remaining 108 stores, 30 were randomly selected for this observational study. A sample size of 30 stores 
was used due to the available resources for data collection. With a full population of 108 stores, a sample size of 30 stores at a confidence level of .95 returns a margin of error of $15.3 \%$.

Stores were assessed using the Nutritional Environment Measures Survey for Stores (NEMS-S). Full explanation and validation of this tool can be found in previous literature (Glanz et al., 2007). Auditors were trained using the training modules developed for NEMS-S (Honeycutt, Davis, Clawson, \& Glanz, 2010). Each store was audited a minimum of two times, and a maximum of three times, and never by the same auditor. Individual audits were then averaged and used to determine final audit score. Data were collected between April $1^{\text {st }}$ and May $8^{\text {th }}$ 2016, between the hours of 9:00 AM and 4:00 PM. These times and dates were used to provide consistency in data collection. During these times stores are typically stocked, and data are more reliable (Honeycutt et al., 2010). Data collection was limited to that month in order to not let seasonal availability of produce be a factor of produce quality and availability.

Each store was graded with a total NEMS-S score, as well as sub scores for availability, cost, and quality. A maximum total score was 54, which consisted of a maximum of 30 in availability, 18 in cost, and 6 for quality of produce (Glanz et al., 2007). Availability scores were calculated based on the total number of healthier options available. The method explained below was previously developed and a validated method for testing availability (Glanz et al., 2007). For milk, stores earned 2 points if they have low-fat/skim milk, and an additional point if they had a $>50 \%$ ratio of lowest-fat to whole. For fruits and vegetables, they earned points based on the varieties available (out of 10). If they had 0 varieties they would earn 0 points, $<5$ varieties was worth 1 point, 5-9 varieties was worth 2 points, and all 10 varieties was worth 3 points. Ground beef earned 2 points if they had 90\% lean meat (or leaner), 1 additional point if they had 2-3 varieties of lean meat, and 2 
additional points if they had $>3$ varieties. Hot dogs earned 2 points if they had fat free, or 1 point if they had light, but not fat-free hot dogs. Frozen dinners earned 3 points if they had 3 different options, or 2 points if they had 1 or 2 options. Baked goods earned 2 points if they had low-fat items. If a store had diet soda or 100\% juice they would earn 1 point for each option of beverage. A store offering whole grain bread would earn 2 points, and if they had $>2$ varieties of whole wheat bread they would earn an additional point. If a store had baked chips they would earn 2 points, and an additional point if they had $>2$ varieties of baked chips. Finally, if they offered a cereal with $<7 \mathrm{~g}$ sugar per serving they would earn 2 points. Final score for availability could range from 0 to 30 .

Cost was calculated based on comparison between healthier and less healthy options. The method explained below is a previously developed and validated method for testing cost (Glanz et al., 2007). For milk, if the lowest available fat percentage was cheaper than whole milk the store was awarded 2 points, if it was the same cost they were awarded 1 point, and if whole milk was cheaper they were awarded -1 . For all other foods mentioned previously, if the healthier option was more expensive a store received a score of -1 . If the healthier option was less expensive, they received a score of 2 . Fruit and vegetables are not used in the cost calculation because there are not healthier options for fruits and vegetables. Final score for cost could range from -9 to 18 . Negative numbers indicate that healthier options are more expensive than their less healthy counterparts.

Quality measured only fruits and vegetables, and it was based on the percent of options that were acceptable. The method explained below was previously developed and a validated method for testing quality (Glanz et al., 2007). Acceptability was defined as produce in peak condition, top quality, good color, fresh, firm and clean (Glanz et al., 2015). If $25-49 \%$ were acceptable, the store received 1 point. If $50-74 \%$ were acceptable, the store was awarded 2 points, and if $\geq 75 \%$ was acceptable the store was awarded 3 points. Scoring 
was done for fruits and vegetables separately, to a maximum of 6 total points. Final score for quality could range from 0 to 6 . Table 4.1 shows full scoring methods. 
Table 4.1

NEMS-S scoring systems for the different types of foods

\begin{tabular}{|c|c|c|c|c|}
\hline & Item & Availability & Price & Quality* \\
\hline 5. & Milk & $\begin{array}{l}\text { YES low-fat/skim }=2 \text { points }(\mathrm{pts}) \\
\text { Proportion (lowest-fat to whole) } \geq 50 \% \\
=1 \text { point }(\mathrm{pt})\end{array}$ & $\begin{array}{l}\text { Lower for lowest-fat (low-fat/skim) }=2 \\
\text { pts } \\
\text { Same for both }=1 \mathrm{pt} \\
\text { Higher for low-fat }=-1 \mathrm{pt}\end{array}$ & - not applicable - \\
\hline 6. & Fruit & $\begin{array}{l}0 \text { varieties }=0 \mathrm{pts} \\
<5 \text { varieties }=1 \mathrm{pt} \\
5-9 \text { varieties }=2 \mathrm{pts} \\
10 \text { varieties }=3 \mathrm{pts}\end{array}$ & - not applicable - & $\begin{array}{l}25-49 \% \text { acceptable }=1 \mathrm{pt} \\
50-74 \% \text { acceptable }=2 \\
\text { pts } \\
75 \%+\text { acceptable }=3 \mathrm{pts}\end{array}$ \\
\hline 7 . & Vegetables & $\begin{array}{l}0 \text { varieties }=0 \mathrm{pts} \\
<5 \text { varieties }=1 \mathrm{pt} \\
5-9 \text { varieties }=2 \mathrm{pts} \\
10 \text { varieties }=3 \mathrm{pts}\end{array}$ & - not applicable - & $\begin{array}{l}25-49 \% \text { acceptable }=1 \mathrm{pt} \\
50-74 \% \text { acceptable }=2 \\
\text { pts } \\
75 \%+\text { acceptable }=3 \mathrm{pts}\end{array}$ \\
\hline 8. & Ground Beef & $\begin{array}{l}\text { YES lean meat }=2 \mathrm{pts} \\
2-3 \text { varieties }<10 \% \text { fat }=1 \mathrm{pt} \\
>3 \text { varieties }<10 \% \text { fat }=2 \mathrm{pts}\end{array}$ & $\begin{array}{l}\text { Lower for lean meat }=2 \mathrm{pts} \\
\text { Higher for lean meat }=-1 \mathrm{pt}\end{array}$ & - not applicable - \\
\hline 9. & Hot dogs & $\begin{array}{l}\text { YES fat-free available }=2 \mathrm{pts} \\
\text { Light, but not fat-free }=1 \mathrm{pt}\end{array}$ & $\begin{array}{l}\text { Lower for fat-free or light }=2 \mathrm{pts} \\
\text { Higher for fat-free or light }=-1 \mathrm{pt}\end{array}$ & - not applicable - \\
\hline 10. & $\begin{array}{l}\text { Frozen } \\
\text { dinners }\end{array}$ & $\begin{array}{l}\text { YES all } 3 \text { reduced-fat types }=3 \mathrm{pts} \\
\text { YES } 1 \text { or } 2 \text { reduced-fat types }=2 \mathrm{pts}\end{array}$ & $\begin{array}{l}\text { Lower for reduced-fat (based on } \\
\text { majority of frozen dinners) }=2 \mathrm{pts} \\
\text { Higher for reduced-fat }=-1 \mathrm{pt}\end{array}$ & - not applicable - \\
\hline 11. & Baked goods & YES low-fat items $=2 \mathrm{pts}$ & $\begin{array}{l}\text { Lower for low-fat }(\text { per piece })=2 \mathrm{pts} \\
\text { Higher for low-fat }(\text { per piece })=-1 \mathrm{pt}\end{array}$ & - not applicable - \\
\hline 12. & Beverages & $\begin{array}{l}\text { YES diet soda }=1 \mathrm{pt} \\
\text { YES } 100 \% \text { juice }=1 \mathrm{pt}\end{array}$ & $\begin{array}{l}\text { Lower for diet soda }=2 \mathrm{pts} \\
\text { Higher for } 100 \% \text { juice }=-1 \mathrm{pt}\end{array}$ & - not applicable - \\
\hline 13. & Bread & $\begin{array}{l}\text { YES whole grain bread }=2 \mathrm{pts} \\
>2 \text { varieties whole wheat bread }=1 \mathrm{pt}\end{array}$ & $\begin{array}{l}\text { Lower for whole wheat }=2 \mathrm{pts} \\
\text { Higher for whole wheat }=-1 \mathrm{pt}\end{array}$ & - not applicable - \\
\hline 14. & Baked chips & $\begin{array}{l}\text { YES baked chips }=2 \mathrm{pts} \\
>2 \text { varieties baked chips }=1 \mathrm{pt}\end{array}$ & $\begin{array}{l}\text { Lower for baked chips }=2 \mathrm{pts} \\
\text { Higher for baked chips }=-1 \mathrm{pt}\end{array}$ & - not applicable - \\
\hline 15. & Cereal & YES healthier cereal $=2 \mathrm{pts}$ & $\begin{array}{l}\text { Lower for healthier cereal (per box) }=2 \\
\text { pts } \\
\text { Higher for healthier cereal (per box) }=- \\
1 \text { pt }\end{array}$ & - not applicable \\
\hline
\end{tabular}

(Glanz et al., 2015) 
Demographic data were gathered for the census tract where each store was located. Demographic data that were evaluated included percent White residents, total household income, percent of residents in poverty, and family size. Total percent Poverty Income Ratio (PIR) was also calculated. To calculate PIR, federal guidelines for poverty were used and adjusted based on family size. Store type was identified as national chain or non־national chain. Stores that were identified as non-national chain stores were local, independent, and ethnic markets.

Differences in NEMS-S scores were obtained by either Kruskal-Wallis test or Analysis of Variance as appropriate using SPSS. Availability scores were not normally distributed; therefore, a Kruskal-Wallis test was used. Analysis of Variance was used to identify differences in cost and quality. Significance was set at $\leq 0.05$ level. Analysis of Variance was used to compare demographic variables to dependent variables.

\section{Results}

Demographic variables, availability, quality, and cost scores can be seen in Table 4.1. Availability scores ranged from $5-25$, with a mean $21.1( \pm 4.89)$. Total possible range for availability scores was $0-30$. Cost scores ranged from -4 to 2 , with a mean $-1( \pm 1.3)$. Total possible range for cost scores was -9-18. Quality scores ranged from 5-6, with a mean of $5.9( \pm 0.3)$. Total possible range for quality scores range from 0-6.

Data from the different census tracts the stores were located in had percent white residents ranging from $53.0 \%$ to $93.5 \%$, with a mean of $78.6 \%$. The range for family size was from 1.44 family members to 3.99 family members with a mean of 2.36 . PIR was analyzed and split in groups of $150 \%$ poverty, $200 \%$ poverty, $300 \%$ poverty, and $\geq 400 \%$ poverty.

For national chain stores the mean NEMS-S score for availability was 22.92 , the mean for cost was -.68 , and the mean for quality was 6 . For the non-national stores the 
mean for availability was 12 , the mean for cost was -1 , and the mean for quality was 5.4 . All five stores that were classified as non-national chain markets came in under the mean of all 30 stores for availability, quality, and cost. 
Table 4.2

Store type, NEMS-S scores, and demographic information of the census tract area for the audited stores in Denver, $\mathrm{CO}$

\begin{tabular}{|c|c|c|c|c|c|c|c|}
\hline Store Type & Availability & Cost & Quality & $\begin{array}{c}\text { White } \\
\%\end{array}$ & Income $^{1}$ & $\begin{array}{c}\text { Family } \\
\text { Size }^{2}\end{array}$ & $\mathrm{PIR}^{3}$ \\
\hline National Chain & 24 & 1 & 6 & 78.5 & 64,392 & 2.2 & 3.0 \\
\hline National Chain & 24 & 2 & 6 & 80.9 & 110,450 & 2.1 & 4.0 \\
\hline National Chain & 20 & -2 & 6 & 90.9 & 107,543 & 2.0 & 4.0 \\
\hline National Chain & 20 & -2 & 6 & 93.5 & 149,753 & 1.5 & 4.0 \\
\hline National Chain & 24 & -1 & 6 & 84.6 & 54,451 & 1.4 & 3.0 \\
\hline National Chain & 25 & -3 & 6 & 55.2 & 39,130 & 3.0 & 1.5 \\
\hline National Chain & 24 & -1 & 6 & 63.5 & 52,293 & 3.2 & 2.0 \\
\hline National Chain & 24 & 2 & 6 & 73.4 & 43,288 & 2.2 & 2.0 \\
\hline National Chain & 24 & -2 & 6 & 65.4 & 60,343 & 2.0 & 2.5 \\
\hline National Chain & 23 & 0 & 6 & 69.6 & 59,592 & 2.8 & 3.0 \\
\hline National Chain & 25 & 0 & 6 & 88.9 & 101,725 & 2.1 & 4.0 \\
\hline National Chain & 24 & -1 & 6 & 82.3 & 89,369 & 2.3 & 4.0 \\
\hline National Chain & 24 & -1 & 6 & 86.0 & 68,329 & 2.6 & 3.0 \\
\hline National Chain & 21 & 0 & 6 & 84.6 & 54,451 & 1.4 & 3.0 \\
\hline National Chain & 23 & -2 & 6 & 90.4 & 82,229 & 2.0 & 4.0 \\
\hline National Chain & 24 & 0 & 6 & 55.2 & 39,130 & 3.0 & 1.5 \\
\hline National Chain & 23 & -1 & 6 & 84.2 & 62,718 & 2.0 & 3.0 \\
\hline National Chain & 21 & 0 & 6 & 90.9 & 107,543 & 2.0 & 4.0 \\
\hline National Chain & 23 & -1 & 6 & 88.9 & 101,725 & 2.1 & 4.0 \\
\hline National Chain & 25 & -2 & 6 & 93.5 & 149,753 & 1.5 & 4.0 \\
\hline National Chain & 21 & -1 & 6 & 76.6 & 73,880 & 1.9 & 4.0 \\
\hline National Chain & 21 & -2 & 6 & 82.3 & 89,369 & 2.3 & 4.0 \\
\hline National Chain & 22 & -1 & 6 & 90.9 & 107,543 & 2.0 & 4.0 \\
\hline National Chain & 21 & 1 & 6 & 71.7 & 44,721 & 1.8 & 2.5 \\
\hline National Chain & 23 & 0 & 6 & 53.0 & 46,175 & 4.0 & 1.5 \\
\hline Non-National Market & 6 & -1 & 6 & 69.1 & 51,562 & 3.1 & 2.5 \\
\hline Non-National Market & 17 & -4 & 5 & 85.1 & 148,454 & 2.3 & 4.0 \\
\hline Non-National Market & 13 & 0 & 5 & 84.6 & 43,825 & 3.3 & 2.0 \\
\hline Non-National Market & 5 & 0 & 5 & 68.9 & 38,793 & 3.7 & 1.5 \\
\hline Non-National Market & 19 & 0 & 6 & 74.7 & 49,051 & 2.9 & 2.0 \\
\hline
\end{tabular}

${ }^{1}$ Average family income, in dollars, for the census tract demographics for the stores location

${ }^{2}$ Family size, in persons, for the census tract demographics for the stores location ${ }^{3} \mathrm{PIR}$ - poverty income ratio, the amount of times per federal poverty level the average family in each census tract was - calculated based on federal poverty guidelines, corrected for family size. 
Availability $(\mathrm{P}=.78)$, cost $(\mathrm{P}=.36)$, and quality $(\mathrm{P}=.59)$ were not found to have significant differences when comparing PIR groups. Likewise, when testing for White resident percent, availability $(\mathrm{P}=.49)$, cost $(\mathrm{P}=.15)$, and quality $(\mathrm{P}=.22)$ were also found to not have significant differences between groups. Income and family size were not tested separately as PIR takes into account both factors.

Significant differences were found for store type for both availability $(\mathrm{P}=.000)$, and quality $(\mathrm{P}=.000)$. There was no significant difference found for cost between the national and non-national markets $(\mathrm{P}=.63)$. Auditors found that only 3 stores had food that was not of acceptable quality, and these were all at non-national chain stores. There were no significant correlations between the location of these stores and any ethnic and sociodemographic data.

\section{Discussion}

While other cities have shown potential food access equity issues (Hendrickson et al., 2006), Denver may not face those same issues. Although we did not find significant differences at the pre-defined significance level of .05, we would like to propose that there is still a potential for differences in cost in Denver. When we tested for differences in cost as it relates to White \% we found a significance level of .15. This $\mathrm{P}$ value is much lower than the other variables tested, and leads us to believe there is some potential differences there. This is an area that merits further consideration in the future, as .15 levels still gives some cause for concern that differences exist. There is less reason to believe there are differences in availability or quality when testing for White \%. PIR appears to lack significant differences across availability, quality, and cost.

As noted, the smaller ethnic and local markets afford less availability and poorer quality. Although these residents have the choice of going to large markets and having equal access to foods, they still may not be shopping at these large stores. Just because 
someone has equivalent access does not mean they are purchasing equivalent foods. As noted previously, evidence shows that those with low-income consume less produce (Drewnowski \& Specter, 2004). The lack of acceptable produce quality in these smaller local stores may be a reason these shoppers are not choosing fruits and vegetables. Even though there was ample selection of produce of acceptable quality at the national markets, consumers with low income may choose not to shop at these locations. Often, people choose to shop at grocery stores closest to them (Fiechtner et al., 2016). This may be particularly true people with low income who do not have the time or means of transportation to choose stores based on any criteria other than geographical location. Identifying what the cause of obesity in these minority populations would be valuable. As noted earlier, there are noted correlations between obesity rates and low-income populations (Drewnowski \& Specter, 2004). There could be some relation between the lower quality produce we found in small markets to obesity levels in the Denver area. Studies have identified health inequity issues because residents of neighborhoods with better access to healthy, fresh food have lower BMI, lower levels of obesity, and overall healthier diets (Larson et al., 2009). The fact that these lower-income areas do have higher BMI's on average (Kincheloe et al., 2013), imply there are some food related health disparities.

There are many logical reasons that these small, ethnic markets may have less availability and poorer quality. First, the economics of the grocery store business are of concern as stores that sell more volume of food have an easier time moving produce. Produce quality scores showed that this occurs in the smaller markets. Since fresh produce is perishable, the less food a store sells, the harder it is to keep fresh food on site. Second, these smaller markets which are ethnic stores are marketing toward a specific ethnic demographic. It was not surprising to find a lack of milk or whole wheat bread in the Asian markets visited. In fact, those stores had no milk or bread available at all. Research has 
shown that as South Asian immigrants adjusted to a Western diet, they have faced increased risks of developing obesity, diabetes, and cardiovascular disease (HolmboeOttesen \& Wandel, 2012). Furthermore, dietary quality of most Hispanic immigrants is very poor in the United States (Pérez-Escamilla, 2009). In both immigrant groups, confounding factors are at play; however, the food choices available in their grocery stores were not noted in these studies as a potential cause of poor dietary intake. However, as seen in our study, the ethnic markets do have less healthful options available. Some of these scores were artificially deflated because NEMS-S does not consider cultural options in these stores. Some of the ethnic markets did not carry milk or bread, which may not be a culturally appropriate choice for individuals with those demographics. Perhaps individuals shopping at these ethnic markets are facing food availability and quality issues. Furthermore, these individuals may not have purchased milk or bread even if they were available. The overwhelming majority of minority populations in Denver are either Asian or Hispanic (Current Population Survey, 2014), so there is reason to be concerned about the dietary habits of these populations. Denver faces many health disparities, where minorities are often of worse health status (Kincheloe et al., 2013).

The major limitation of this study is that we may not be able to make larger inferences for some of the populations outside of Denver. Many of the grocery stores bring independence into question as they may be supplied by the same distributor. In the sample there are many stores from the same chain since that is the most common super market inside Denver. Major food distributors likely supply food to many of these locations. This means the quality of the food at each particular store may not be independent of another. The other significant limitation was that although there were significant differences between the large chains and the small markets, the total sample size of the small markets was limited. Significantly more major national supermarkets are available than local, 
ethnic markets. These local, ethnic markets likely serve a niche part of the market.

However, no research has been done to identify actual shopping behaviors of people near these markets. A final limitation of this study is that the NEMS-S system does not test for culturally acceptable healthy alternatives. Despite not having milk, bread, or hot dogs, it is possible an ethnic market provides nutritious food in other ways. This, again, calls for a need of future research in determining behaviors of shoppers.

\section{Conclusion}

We found no significant differences overall among grocery stores in availability, cost, or quality of foods based on NEMS-S scoring due to ethnic or socioeconomic census status at the $\mathrm{P}=.05$ level. There are perhaps differences in cost in White \% neighborhoods, as recognized by $\mathrm{P}=.15$. There were significant differences when comparing large, national supermarket chains with small independent, and ethnic markets in availability and quality.

This study calls for potential future research that would be of value. First, it would be beneficial to understand the shopping or decision making behaviors of individuals who utilize these markets. As noted, there are equal alternatives in Denver due to the large number of national markets available. However, it is not clear who is using these markets. While the local, ethnic markets may only serve a niche role, they could also be the primary shopping center for certain populations. It is possible the lack of possibilities for produce and other foods in these local markets could play a role in health outcomes. Denver does have a correlation between obesity rates and income level (Kincheloe et al., 2013). Further research based on identifying factors that lead to this disparity in obesity rates would be worthwhile. Obesity is a risk factor for many other diseases. There are likely some dietary differences which lead to this difference in obesity, so looking beyond the store options and into dietary habits is valuable. Second, Denver appears to be different from other 
populations that have seen significant differences in their grocery stores (Hendrickson et al., 2006). Future research centered on why this market is different in that sense could prove valuable. Furthermore, not all previous research has used NEMS-S so it could be of value to identify if different methods reach the same conclusions in these areas. 


\section{CHAPTER V. SUMMARY}

Health disparity is an increasingly problematic issue that we are facing in the United States (Fiscella \& Williams, 2004). Previous research has shown that food inequality can lead to poorer health outcomes, and obesity rates are highest among the lowest income (Drewnowski \& Specter, 2004). Part of this problem is because foods that are highest in energy and sugar are also the least expensive (Drewnowski \& Eichelsdoerfer, 2010). This means that those facing significant budget problems may have trouble affording healthier foods, including produce. Further research has shown that the issue is more complex than simply the cost of goods. Some lower-income, communities of color, have less access to healthy foods (Treufaht \& Karpyn, 2010). The links between food access and health status (Ploeg, 2010) raise concerns about health disparities based on race and income due to food access issues.

Denver, CO faces many of the same health disparities that are seen around the country, where minorities have significantly poorer health status (Kincheloe et al., 2013). Using the Nutrition Environment Measure Survey-Supermarkets (NEMS-S), 30 grocery stores throughout the Denver area were evaluated for availability, cost, and quality of foods. The results of this study found that unlike other areas of the country, no significant differences were evident in the availability, cost, or quality of produce because of relative income or ethnicity. Despite not being significant at $\mathrm{P}=.05$, there are potential differences in cost when compared to percentage of White residents. The result of $\mathrm{P}=.15$ for these areas give concern that there are some differences, and it may need further consideration. However, larger grocery stores were more likely to have higher availability of certain foods

like bread and milk. Moreover, larger grocery stores were more likely to have higher quality of produce compared to smaller local, ethnic markets. Nevertheless, cost was not higher between both sizes of stores if the smaller store carried the product. The results of 
this study did not find any significant differences in produce quality based on relative income or ethnicity. Quality differences were found based on store size. Larger, national chain grocery stores were more likely to have higher quality produce.

This study was limited by the fact that it is not safe to make assumptions about the rest of the country based on these results. It is reasonable to assume that the stores were not truly independent. This means that Denver is defined as the population of this study, not the sample. This study suggests a clear need for future research. First, it would be appropriate to look at actual human behaviors in these environments. It was clear that an individual could appropriately shop regardless of location if they picked a major supermarket. If this same resident was only shopping at small, local markets, they may have limited choices. Just because an individual could shop at one of the major markets, there is no reason to think that is actually what they are doing.

This study suggests many opportunities for future research. Identifying exactly who is shopping at these smaller markets, and if it is their primary source of food would be an important discovery. It is possible that shoppers could be experiencing worse food options if they are using only the smaller, ethnic markets. It would be valuable to determine choices that residents are making in not only food choices, but also store choices. Further research could also look at the differences in Denver food delivery and other cities. Other studies have shown significant differences in certain cities (Powell et al., 2007), so the fact Denver does not show these differences is interesting to note. Further research could also be done within the city of Denver to test cost of produce between stores. 


\section{REFERENCES}

Child Health USA 2013. (2013). Rockville, Maryland Retrieved from http://mchb.hrsa.gov/chusa13/.

Current Population Survey. (2014). Retrieved from https://www.census.gov/cps/data/.

Abu-Ouf, N., \& Jan, M. (2015). The impact of maternal iron deficiency and iron deficiency anemia on child's health. Saudi Medical Journal, 36(2), 146-149. doi:10.15537/smj.2015.2.10289

Braveman, P. (2014). What are health disparities and health equity? we need to be clear. Public Health Reports, 129 Supplement 2, 5-8.

Braveman, P., Cubbin, C., Egerter, S., Williams, D., \& Pamuk, E. (2010). Socioeconomic disparities in health in the United States: what the patterns tell us. American Journal of Public Health, 100 Supplement 1, S186-196. doi:10.2105/AJPH.2009.166082

Braveman, P., \& Gottlieb, L. (2014). The social determinants of health: it's time to consider the causes of the causes. Public Health Reports, 129 Supplement 2, 19-31.

Braveman, P., Kumanyika, S., Fielding, J., Laveist, T., Borrell, L., Manderscheid, R., \& Troutman, A. (2011). Health disparities and health equity: the issue is justice. American Journal of Public Health, 101 Suppl 1, S149-155. doi:10.2105/AJPH.2010.300062

Caspi, C., Kawachi, I., Subramanian, S., Adamkiewicz, G., \& Sorensen, G. (2012). The relationship between diet and perceived and objective access to supermarkets among low-income housing residents. Social Science and Medicine, 75(7), 1254-1262. doi:10.1016/j.socscimed.2012.05.014 
Cummins, S., Flint, E., \& Matthews, S. (2014). New neighborhood grocery store increased awareness of food access but did not alter dietary habits or obesity. Health Affairs, 33(2), 283-291. doi:10.1377/hlthaff.2013.0512

Darmon, N., \& Drewnowski, A. (2015). Contribution of food prices and diet cost to socioeconomic disparities in diet quality and health: a systematic review and analysis. Nutrition Reviews, 73(10), 643-660. doi:10.1093/nutrit/nuv027

Davis, G., \& You, W. (2010). The Thrifty Food Plan is not thrifty when labor cost is considered. Journal of Nutrition, 140(4), 854-857. doi:10.3945/jn.109.119594

Drewnowski, A., \& Eichelsdoerfer, P. (2010). Can low-income Americans afford a healthy diet? Nutrition Today, 44(6), 246-249. doi:10.1097/NT.0b013e3181c29f79

Drewnowski, A., \& Specter, S. (2004). Poverty and obesity: the role of energy density and energy costs. American Journal of Clinical Nutrition, 79(1), 6-16.

Escaron, A., Meinen, A., Nitzke, S., \& Martinez-Donate, A. (2013). Supermarket and grocery store-based interventions to promote healthful food choices and eating practices: a systematic review. Preventing Chronic Disease, 10, E50. doi:10.5888/pcd10.120156

Ethan, D., Basch, C., Rajan, S., Samuel, L., \& Hammond, R. (2014). A comparison of the nutritional quality of food products advertised in grocery store circulars of highversus low-income New York City zip codes. International Journal of Environmental Research and Public Health, 11(1), 537-547. doi:10.3390/ijerph110100537

Evans, A., Banks, K., Jennings, R., Nehme, E., Nemec, C., Sharma, S., . . Yaroch, A. (2015). Increasing access to healthful foods: a qualitative study with residents of low-income communities. The International Journal of Behavioral Nutrition and Physical Activity, 12 Supplement 1, S5. doi:10.1186/1479-5868-12-S1-S5 
Fiechtner, L., Kleinman, K., Melly, S., Sharifi, M., Marshall, R., Block, J., . . Taveras, E. M. (2016). Effects of proximity to supermarkets on a randomized trial studying interventions for obesity. American Journal of Public Health, 106(3), 557-562. doi:10.2105/AJPH.2015.302986

Fiscella, K., \& Williams, D. (2004). Health disparities based on socioeconomic inequities: implications for urban health care. Academic Medicine, $79(12), 1139-1147$.

Fuller, D., Engler-Stringer, R., \& Muhajarine, N. (2015). Examining food purchasing patterns from sales data at a full-service grocery store intervention in a former food desert. Preventative Medicine Reports, 2, 164-169. doi:10.1016/j.pmedr.2015.02.012

Gase, L., DeFosset, A., Smith, L., \& Kuo, T. (2014). The association between self-reported grocery store access, fruit and vegetable intake, sugar-sweetened beverage consumption, and obesity in a racially diverse, low-income population. Front Public Health, 2, 229. doi:10.3389/fpubh.2014.00229

Glanz, K., Clawson, M., Davis, E., \& Green, S. (2015). Nutrition Environment Measures Survey. Retrieved from http://www.med.upenn.edu/nems/index.shtml

Glanz, K., Sallis, J., Saelens, B., \& Frank, L. (2007). Nutrition Environment Measures Survey in stores (NEMS-S): development and evaluation. American Journal of Preventive Medicine, 32(4), 282-289. doi:10.1016/j.amepre.2006.12.019

Hartline-Grafton, H., \& Weill, J. (2012). Replacing the thrifty food plan in order to provide adequate allotments for SNAP beneficiaries: Food Research and Action Center.

Hedberg, V. (1994). Malnourished Children in the United States: Caught in the Cycle of Poverty (Vol. 71(2)): Bulletin of the New York Academy of Medicine.

Hendrickson, D., Smith, C., \& Eikenberry, N. (2006). Fruit and vegetable access in four lowincome food deserts communities in Minnesota. Agriculture and Human Values, $23(3), 371-383$. 
Holmboe-Ottesen, G., \& Wandel, M. (2012). Changes in dietary habits after migration and consequences for health: a focus on South Asians in Europe. Food \& Nutrition Research, 56. doi:10.3402/fnr.v56i0.18891

Honeycutt, S., Davis, E., Clawson, M., \& Glanz, K. (2010). Training for and dissemination of the Nutrition Environment Measures Surveys (NEMS). Preventing Chronic Disease, 76), A126.

Horowitz, C., Colson, K., Hebert, P., \& Lancaster, K. (2004). Barriers to buying healthy foods for people with diabetes: evidence of environmental disparities. American Journal of Public Health, 94(9), 1549-1554.

Kincheloe, J., Palacio, M., Butler, D., Shupe, A., \& Ward-Hunt, C. (2013). Health Disparities - the 2013 Report. Exploring health equity in Colorado's 10 winnable battles. Retrieved from Denver, CO: https://www.colorado.gov/pacific/sites/default/files/OHE_Health-Disparities-The2013-Report.pdf

Kindig, D. (2007). Understanding population health terminology. Milbank Quarterly, 85(1), 139-161. doi:10.1111/j.1468-0009.2007.00479.x

Krukowski, R., West, D., Harvey-Berino, J., \& Elaine Prewitt, T. (2010). Neighborhood impact on healthy food availability and pricing in food stores. Journal of Community Health, 35(3), 315-320. doi:10.1007/s10900-010-9224-y

Larson, N., Story, M., \& Nelson, M. (2009). Neighborhood environments: disparities in access to healthy foods in the U.S. American Journal of Preventive Medicine, 36(1), 74-81. doi:10.1016/j.amepre.2008.09.025

LaVeist, T., Gaskin, D., \& Richard, P. (2011). Estimating the economic burden of racial health inequalities in the United States. International Journal of Health Services, $41(2), 231-238$. 
Maillot, M., Darmon, N., \& Drewnowski, A. (2010). Are the lowest-cost healthful food plans culturally and socially acceptable? Public Health Nutrition, 13(8), 1178-1185. doi:10.1017/S1368980009993028

Margetts, B. (2008). Food prices, inequity, and our responsibilities. Public Health Nutrition, 11(5), 437-438. doi:10.1017/S1368980008002139

Martin, K., Ghosh, D., Page, M., Wolff, M., McMinimee, K., \& Zhang, M. (2014). What role do local grocery stores play in urban food environments? A case study of HartfordConnecticut. PloS One, $9(4)$, e94033. doi:10.1371/journal.pone.0094033

Moore, L., \& Diez Roux, A. (2006). Associations of neighborhood characteristics with the location and type of food stores. American Journal of Public Health, 96(2), 325-331. doi:10.2105/AJPH.2004.058040

Morland, K., Diez Roux, A., \& Wing, S. (2006). Supermarkets, other food stores, and obesity: the atherosclerosis risk in communities study. American Journal of Preventive Medicine, 30(4), 333-339. doi:10.1016/j.amepre.2005.11.003

Pampel, F., Krueger, P., \& Denney, J. (2010). Socioeconomic Disparities in Health Behaviors. Annual Review of Sociology, 36, 349-370. doi:10.1146/annurev.soc.012809.102529

Partington, S., Menzies, T., Colburn, T., Saelens, B., \& Glanz, K. (2015). Reduced-item food audits based on the Nutrition Environment Measures Surveys. American Journal of Preventive Medicine, 49(4), e23-33. doi:10.1016/j.amepre.2015.04.036

Pérez-Escamilla, R. (2009). Dietary quality among Latinos: is acculturation making us sick? Journal of the American Dietetic Association, 109(6), 988-991. doi:10.1016/j.jada.2009.03.014

Pi-Sunyer, F. (2002). The medical risks of obesity. Obesity Surgery, 12 Supplement 1, 6S$11 \mathrm{~S}$. 
Ploeg, M. (2010). Access to affordable, nutrition food is limited in "Food Deserts". Retrieved October $30^{\text {th }}, 2016$, from https://naldc.nal.usda.gov/download/40133/PDF

Pollack, C., Cubbin, C., Sania, A., Hayward, M., Vallone, D., Flaherty, B., \& Braveman, P. A. (2013). Do wealth disparities contribute to health disparities within racial/ethnic groups? Journal of Epidemiology and Community Health, 675), 439-445. doi:10.1136/jech-2012-200999

Popkin, B., Duffey, K., \& Gordon-Larsen, P. (2005). Environmental influences on food choice, physical activity and energy balance. Physiology and Behavior, 86(5), 603613. doi:10.1016/j.physbeh.2005.08.051

Powell, L., Slater, S., Mirtcheva, D., Bao, Y., \& Chaloupka, F. (2007). Food store availability and neighborhood characteristics in the United States. Preventive Medicine, 44(3), 189-195. doi:10.1016/j.ypmed.2006.08.008

Rose, D. (2010). Access to healthy food: a key focus for research on domestic food insecurity. Journal of Nutrition, 140(6), 1167-1169. doi:10.3945/jn.109.113183

Seligman, H., Laraia, B., \& Kushel, M. (2010). Food insecurity is associated with chronic disease among low-income NHANES participants. Journal of Nutrition, 140(2), 304310. doi:10.3945/jn.109.112573

Skalicky, A., Meyers, A., Adams, W., Yang, Z., Cook, J., \& Frank, D. (2006). Child food insecurity and iron deficiency anemia in low-income infants and toddlers in the United States. Maternal Child Health Journal, 10(2), 177-185. doi:10.1007/s10995005-0036-0

Treufaht, S., \& Karpyn, A. (2010). The Grocery Gap: Who has Access to healthy food and why it matters. Retrieved from Oakland, CA and Philadelphia, PA: http://thefoodtrust.org/uploads/media_items/grocerygap.original.pdf 
Walker, R, Keane, C., \& Burke, J. (2010). Disparities and access to healthy food in the United States: A review of food deserts literature. Health Place, 16(5), 876-884. doi:10.1016/j.healthplace.2010.04.013

Webber, C., Sobal, J., \& Dollahite, J. (2010). Shopping for fruits and vegetables. Food and retail qualities of importance to low-income households at the grocery store. Appetite, 54(2), 297-303. doi:10.1016/j.appet.2009.11.015

Whitehead, M. (1992). The concepts and principles of equity and health. International Journal of Health Services, 22(3), 429-445.

Williams, D., \& Collins, C. (2001). Racial residential segregation: a fundamental cause of racial disparities in health. Public Health Reports, 116(5), 404-416.

Woolf, S., \& Braveman, P. (2011). Where health disparities begin: the role of social and economic determinants--and why current policies may make matters worse. Health Affairs, 30(10), 1852-1859. doi:10.1377/hlthaff.2011.0685 


\section{APPENDIX A. NEMS-S SURVEY FORMS}

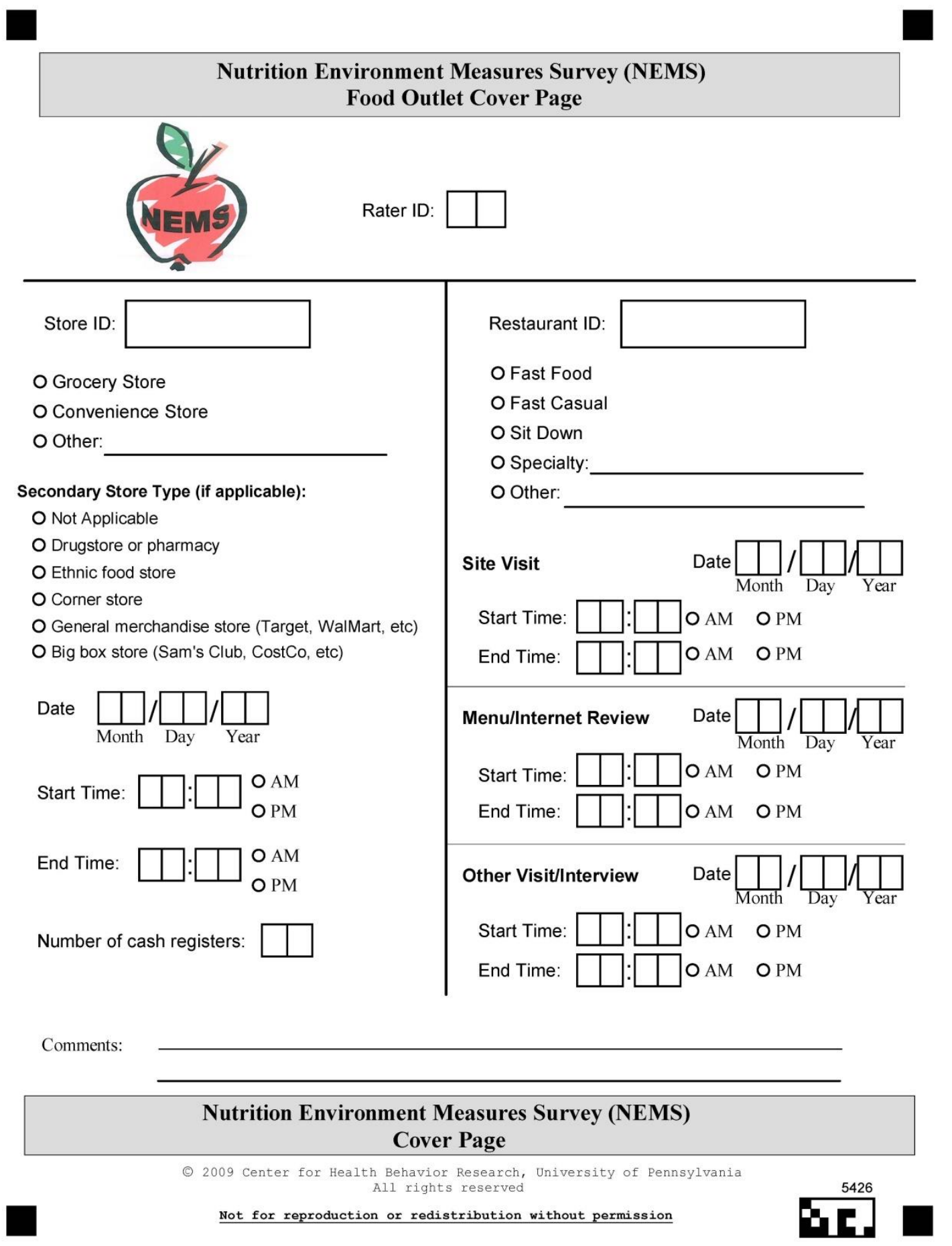

Reprinted from Nutrition Environment Measures Survey, by Glanz, K., Clawson, M., Davis, E., \& Green, S. (2009). Retrieved from http://www.med.upenn.edu/nems/docs/NEMSS.pdf. Copyright 2009 by Center for Health Behavior Research, University of Pennsylvania. Reprinted with Permission. 


\section{Nutrition Environment Measures Survey (NEMS)}

Measure \#1: MILK

Store ID:

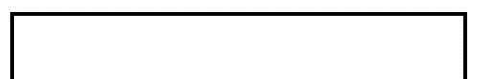

Rater ID:

\section{Marking Instructions}

Please use a pencil or blue or black ink.

Correct

Incorrect $\oslash \otimes$

(-)

1. Is there milk available in this store? Yes $\boldsymbol{O}$ No $\bigcirc$ Comments:

If yes, continue. If no, move on to the next measure.

\section{A. Availability}

Comments:
2. a. Is low-fat (skim or $1 \%$ ) available?
O Yes O No
b. If not, is $2 \%$ available?
O Yes O No ONA

\section{Reference brand}

3. Store brand (preferred)

OYes O No

4. Alternate Brand Name:

Comments:

5. Shelf space: (measure only if low-fat or $2 \%$ milk is available)
Type

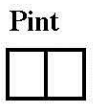
Quart

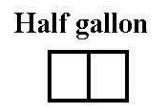
Gallon
a. Lowest fat milk available
O Skim O $1 \% \quad \mathrm{O}_{2 \%}$
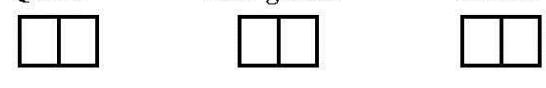

b. Whole
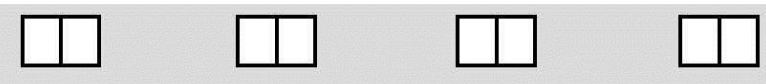

B. Pricing All items should be same brand

Comments:

1. Whole milk, quart

2. Whole milk, half-gallon

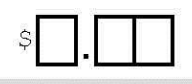

3. Lowest fat milk available, quart

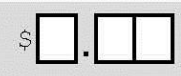

4. Lowest fat milk available, half-gallon
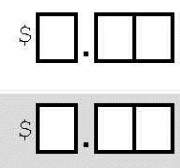

33408

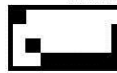




\section{Nutrition Environment Measures Survey (NEMS)}

Measure \#2: FRUIT

Store ID:

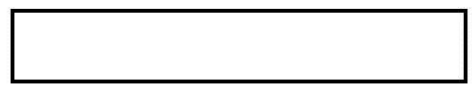

Rater ID:

Does this store sell any fresh fruit? Yes 0 No 0 Comments:

If yes, continue. If no, move on to the next measure.

Availability and Price

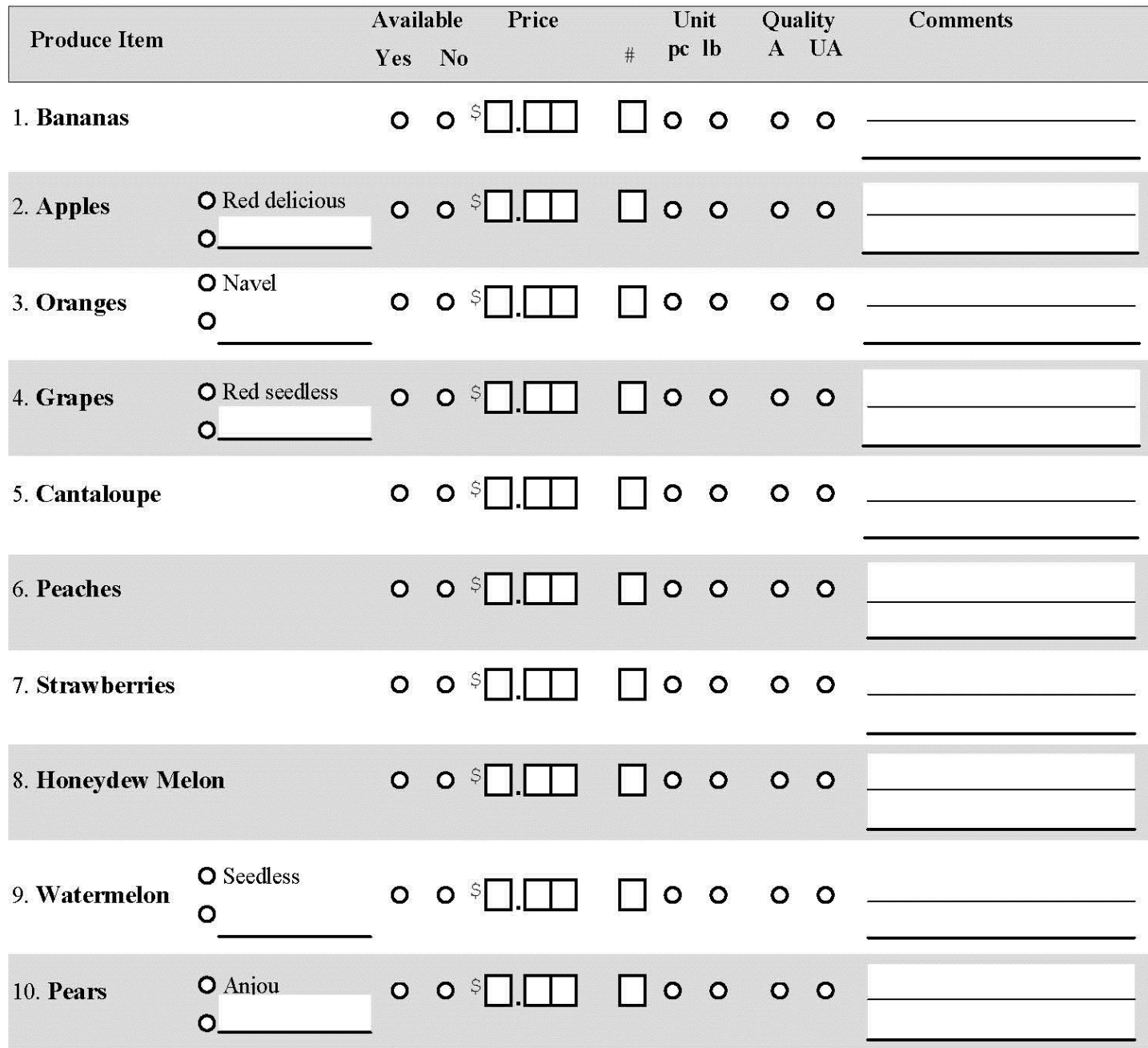

11. Total Types: (Count \# of yes responses)

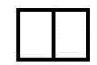




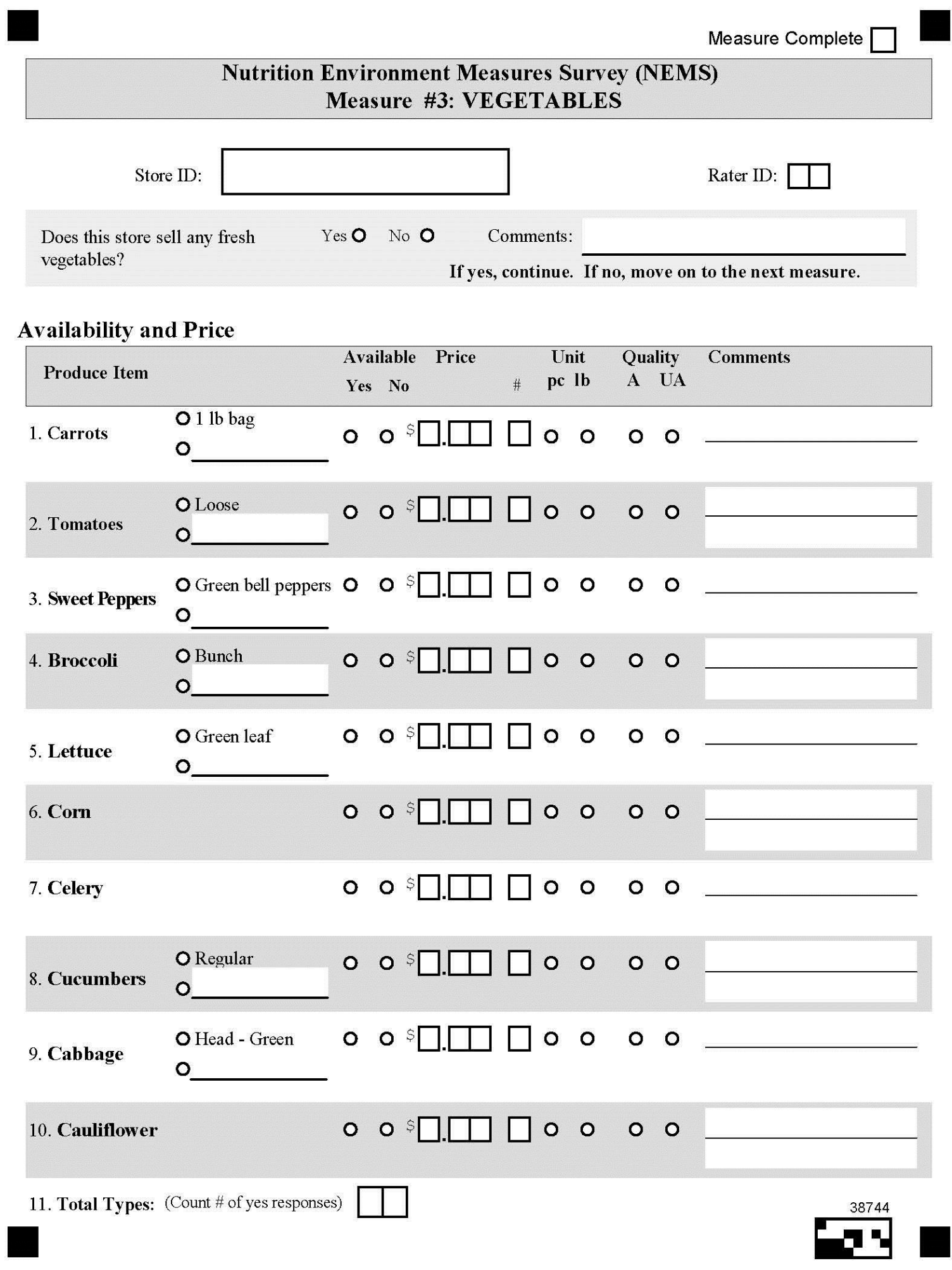




\section{Nutrition Environment Measures Survey (NEMS) \\ MEASURE \#4: GROUND BEEF}

Store ID:

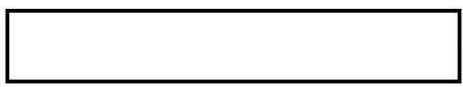

Rater ID:

Does this store sell any beef?

Yes 0 No 0

Comments:

If yes, continue. If no, move on to the next measure.

Availability and Price

\begin{tabular}{|ccc|}
\hline Item & Available & Comments \\
& Yes No N/A Price/lb. & \\
\hline
\end{tabular}

Healthier option:

1. Lean ground beef, $\mathbf{9 0 \%}$ lean, $10 \%$ fat (Ground Sirloin)

○ 0

Alternate Items:

2. Lean ground beef, $(<10 \%$ fat $)$

$\square \%$ fat

$\circ \quad 0 \quad 0 \quad s \square . \square$

3. Ground Turkey, ( $\leq 10 \%$ fat $)$

○ 00 o $\$ \square . \square$

$\square \%$ fat

4. \# of varieties of lean ground beef ( $\leq 10 \%$ fat $)$

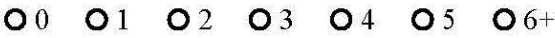

Regular option:

5. St andard ground beef, $80 \%$ lean, $20 \%$ fat ( $G$ round Chuck)

00

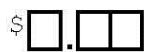

Alternate Item:

Comments

6. Standard alternate ground beef, if above is not available

$0 \quad 0 \quad 0 \quad \$ \square . \square$ $\square \%$ fat 


\section{Nutrition Environment Measures Survey (NEMS)} MEASURE \#5: HOT DOG

Store ID:

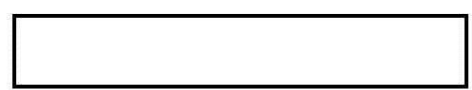

Rater ID:

Does this store sell any hot dogs? Yes $\mathrm{O}$ No $\mathrm{O}$ Comments:

If yes, continue. If no, move on to the next measure.

\section{Availability and Price}

\begin{tabular}{|c|c|c|c|c|}
\hline Item & $\begin{array}{l}\text { Avi } \\
\text { Yes }\end{array}$ & $\begin{array}{l}\text { ilable } \\
\text { No } \text { N/A }\end{array}$ & Price/pkg. & Comments \\
\hline \multicolumn{5}{|l|}{ Healthier option: } \\
\hline $\begin{array}{l}\text { 1. Oscar Mayer } 98 \% \text { Fat-free Wieners } \\
\text { (turkey/beef) } \leq 1 \mathrm{~g} \text { fat }\end{array}$ & 0 & 0 & & \\
\hline \multicolumn{5}{|l|}{ Alternate Item: $(\leq 9 \mathrm{~g}$ fat $)$} \\
\hline $\begin{array}{l}\text { 2. Other:Brand name and type } \\
\text { e.g., Ball Park Fat Free Beef Franks }\end{array}$ & 0 & 00 & oz pkg & Hot dogs/pkg \\
\hline
\end{tabular}

Regular option:

7. Oscar Mayer Wieners

00

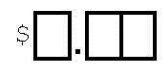

(turkey/pork/chicken)-regular $12 \mathrm{~g}$ fat

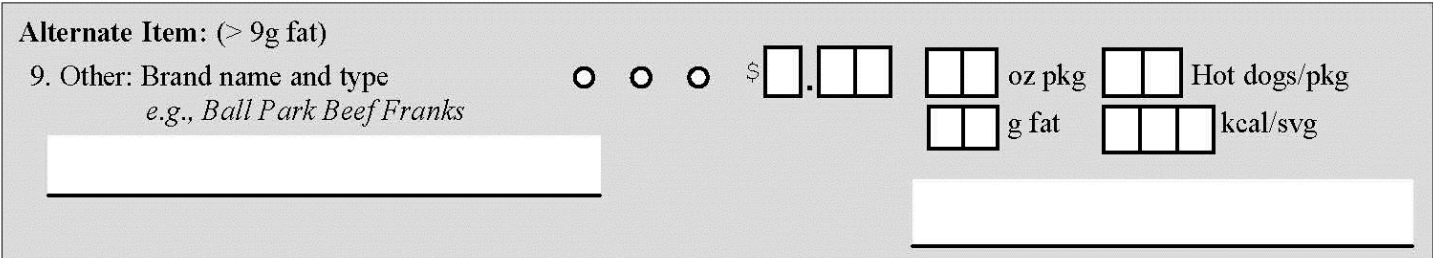




\section{Nutrition Environment Measures Survey (NEMS)}

MEASURE \#6: FROZEN DINNERS

Store ID:

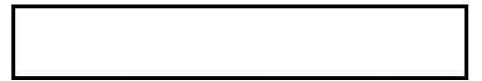

Rater ID:

Does this store sell any frozen

Yes $\mathrm{O}$ No $\mathrm{O}$

Comments:

dinners?

If yes, continue. If no, move on to the next measure.

A. Reference Brand

1. Stouffer's brand (preferred)

O Yes O No

2. Alternate brand (with reduced-fat dinners

available) Brand Name:

Comments:

\section{B. Availability}

1. Are reduced-fat frozen dinners available? ( $\leq 9 \mathrm{~g}$ fat $/ 8-11 \mathrm{oz}$.)

O Yes O No

Shelf space:(measure only if reduced-fat frozen dinners are available)

2. Reduced-fat dinners/regular dinners: Proportion $\quad 0<=10 \% \quad 011-33 \% \quad 034-50 \% \quad 051 \%$

C. Pricing (All items must be same brand)

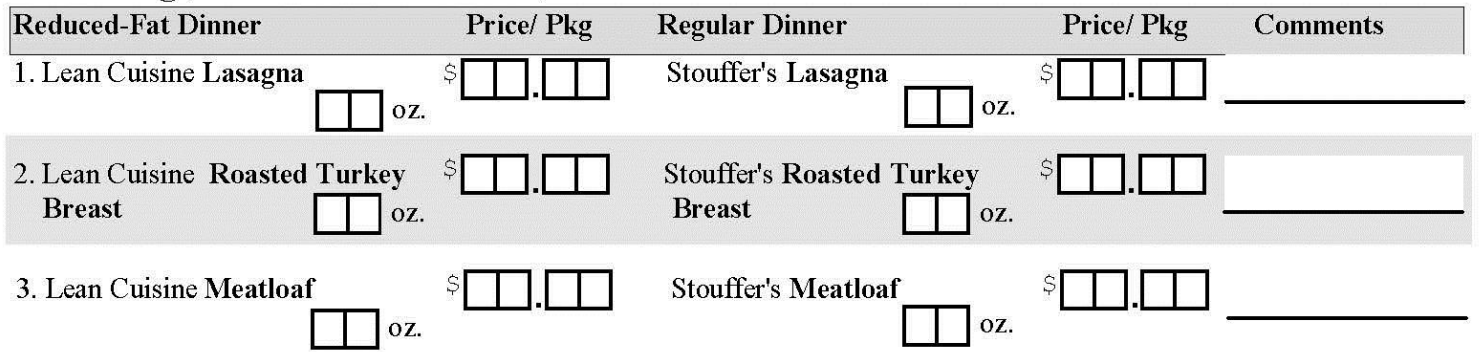

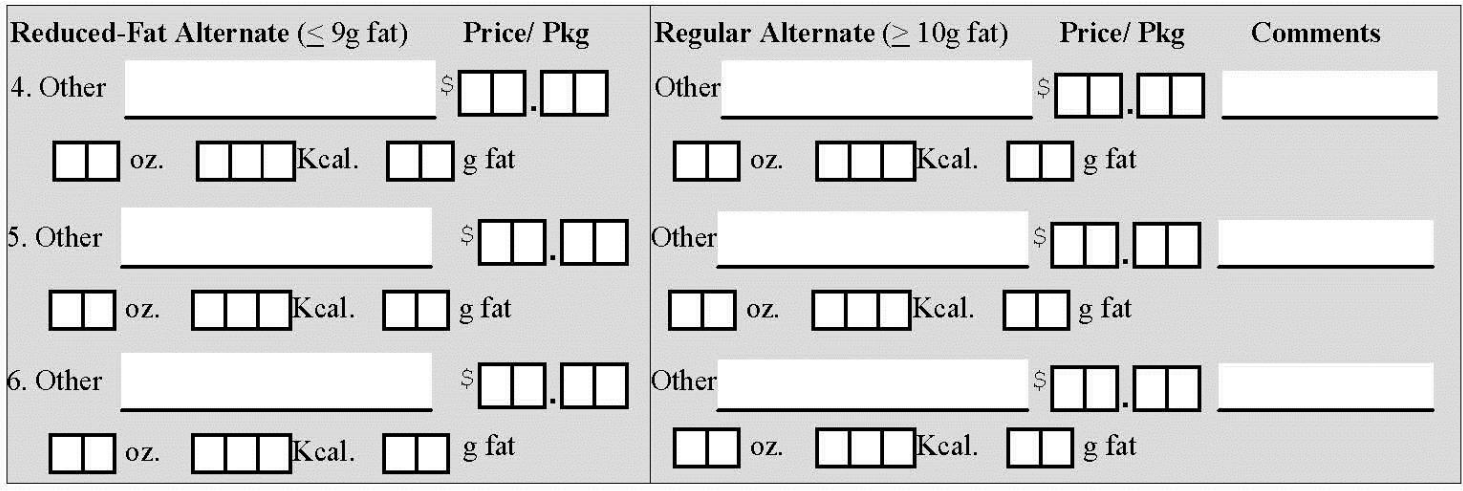

29844 
$\square$

Measure Complete

\section{Nutrition Environment Measures Survey (NEMS)} MEASURE \#7: BAKED GOODS

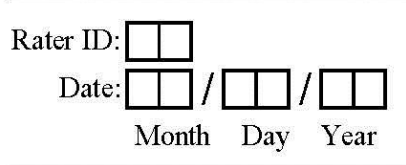

Store ID:

Does this store sell baked goods? Yes $\mathrm{O}$ No $\mathrm{O}$ Comments:

If yes, continue. If no, move on to the next measure.

Availability \& Price

Low-fat baked goods $\leq 3 \mathrm{~g}$ fat/serving

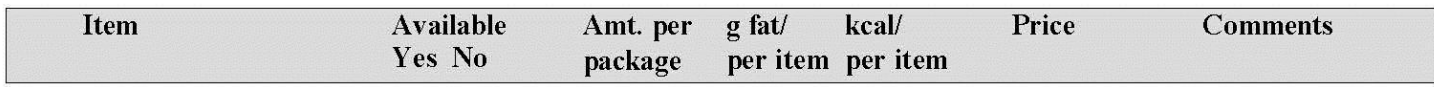

Healthier option:

1. Bagel

$\begin{array}{llll}\text { Single } & 0 & \square & \square\end{array} \square$ \$ $\square . \square$

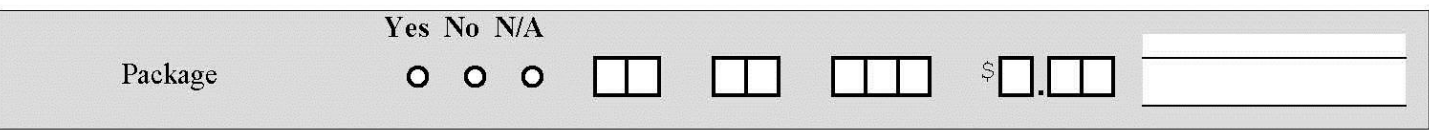

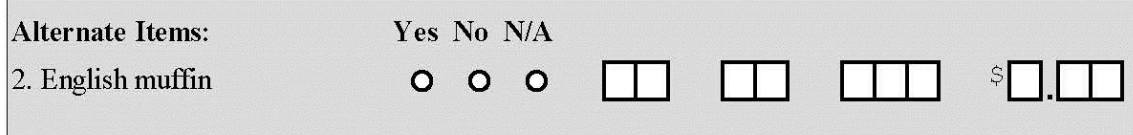

3 a. Low-fat muffin

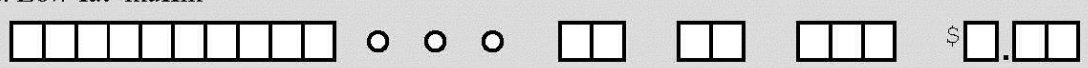

b. \# varieties of low fat muffins $\mathrm{O}_{0} \quad \mathrm{O}_{1} \quad \mathrm{O}_{2} \quad \mathrm{O}_{3}+$

Regular option ( $\geq 4 \mathrm{~g}$ fat/serving or $400 \mathrm{Kcal} /$ serving):
4. Regular muffin
00
$\square \square \square \square \square$
$\$ \square . \square$

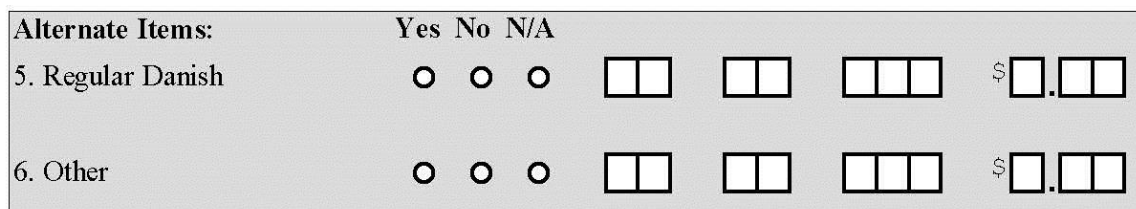




\section{Nutrition Environment Measures Survey (NEMS)}

MEASURE \#8-CS: BEVERAGE

Store ID:

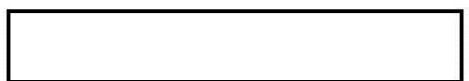

Rater ID:

Does this store sell beverages? Yes $\mathrm{O}$ No $\mathrm{O}$ Comments:

If yes, continue. If no, move on to the next measure.

\section{Availability \& Price}

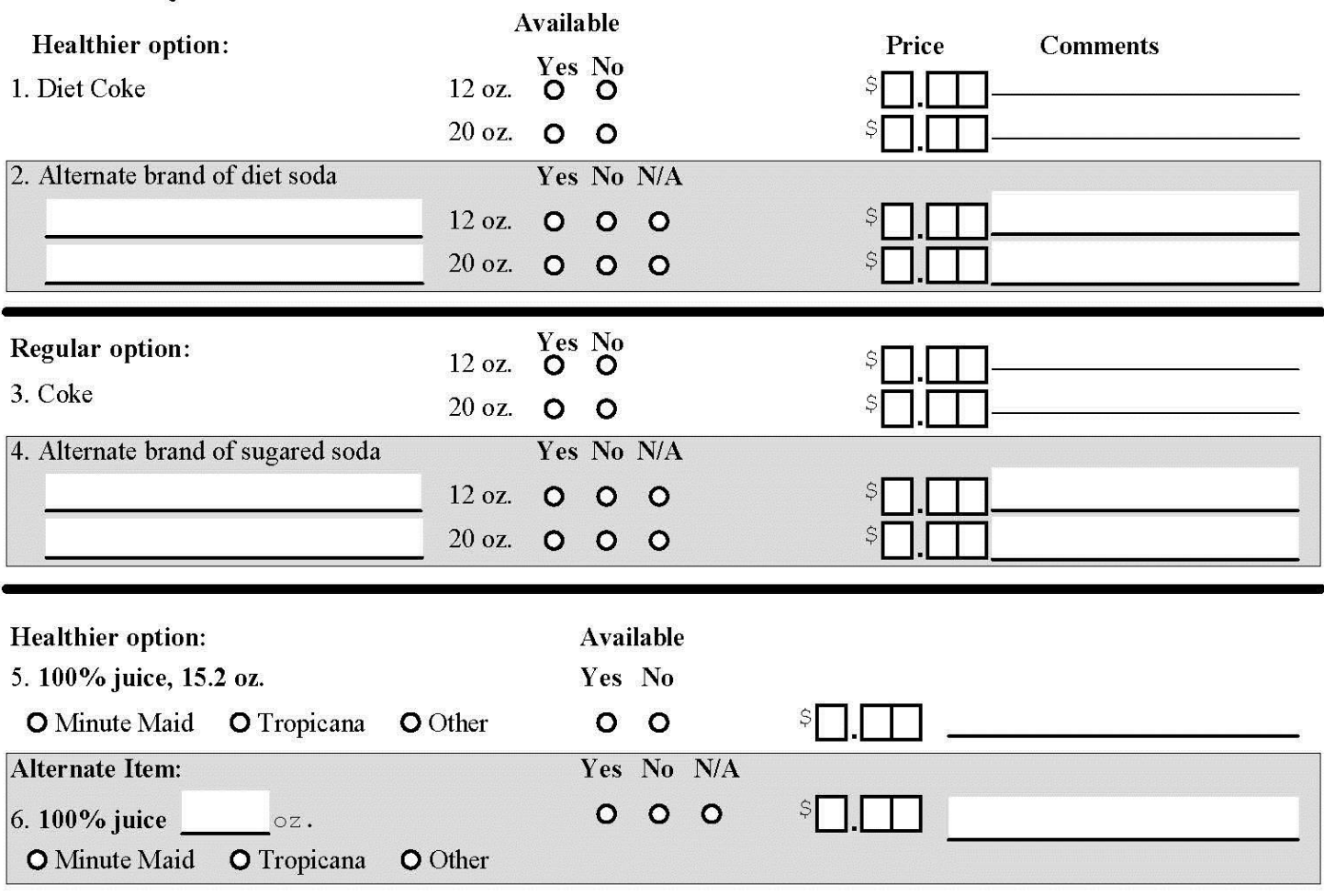

Regular option:

8. Juice Drink, $15.2 \mathrm{oz}$

Yes No

O Minute Maid O Tropicana O Other

○ 0

s $\square$

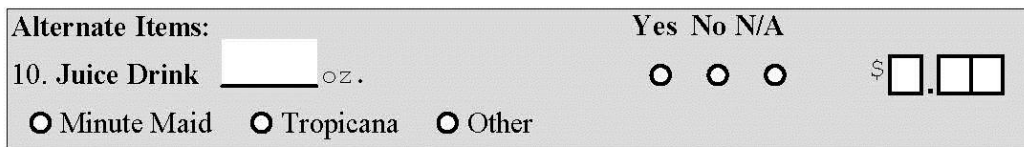




\section{Nutrition Environment Measures Survey (NEMS) MEASURE \#8-GS: BEVERAGE}

Store ID:

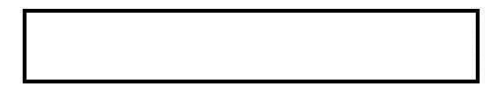

Rater ID

Does this store sell any beverages? Yes $\mathrm{O}$ No $\mathrm{O}$

Comments:

If yes, continue. If no, move on to the next measure.

\section{Availability \& Price}

\section{Available}

Healthier option:

1. Diet Coke

Alternate Item:

Available size Yes No

Price

Comments

12 pack $12 \mathrm{oz}$.

O 0

$\$ \square . \square$

O 12 pack $12 \mathrm{oz}$.

O 6 pack $12 \mathrm{oz}$.

Yes No N/A

O 00

s. $\square$

Regular option:

Yes No

3. Coke

12 pack $12 \mathrm{oz}$.

O 0

Alternate Item:

12 pack $12 \mathrm{oz}$.

O 6 pack $12 \mathrm{oz}$.

Yes No N/A

O 00

$\square . \square$

s $\square . \square$

Healthier option:

Yes No

5. Minute Maid $100 \%$ juice, (64 oz., half gallon)

O $\mathrm{O}$

s $\square . \square$

\begin{tabular}{|lrlll|}
\hline Alternate Items: & Yes No N/A \\
6. Tropicana $100 \%$ juice, $(64 \mathrm{oz}$. , half gallon $)$ & 0 & 0 & 0 & $\$ \square . \square$ \\
7. Other: & 0 & 0 & 0 & $\$ \square . \square$
\end{tabular}

Regular option:

Yes No

8. Minute Maid juice drink, (64 oz., half gallon)

O 0

Alternate Items:

9. Tropicana juice drink, (64 oz., half gallon)

10. Other:

$\begin{array}{cccc}\text { Yes No N/A } & \\ 0 & 0 & 0 & \$ \square . \square \square \\ 0 & 0 & 0 & \$ \square . \square \square\end{array}$

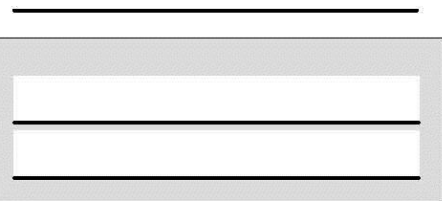

362 


\section{Nutrition Environment Measures Survey (NEMS) \\ MEASURE \#9: BREAD}

Store ID:

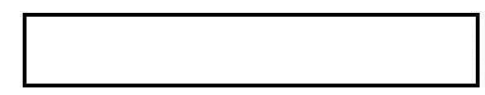

Rater ID

$$
\text { Does this store sell any bread? Yes } \quad \text { No } 0 \quad \begin{gathered}
\text { Comments: } \\
\text { If yes, continue. If no, move on to the next measure. }
\end{gathered}
$$

\section{Availability \& Price}

\begin{tabular}{|cc|}
\hline Item & Available Loaf size Price/loaf Comments \\
& Yes No N/A (ounces)
\end{tabular}

Healthier Option: Whole grain bread ( $100 \%$ whole wheat bread and whole grain bread)

1. Nature's Own $100 \%$ Whole

00

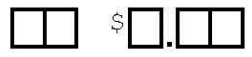
Wheat Bread

Alternate Items:

2. Sara Lee Classic $100 \%$ Whole Wheat Bread

$\circ$ ○ $\circ \square \square: \square . \square$

3. Other:

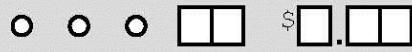

4. \# of varieties of $100 \%$ whole wheat bread and whole grain (all brands)

Regular Option: White bread (Bread made with refined flour)

5. Nature's Own Butter Bread

$\circ 0$

$\square \leqslant \square . \square$

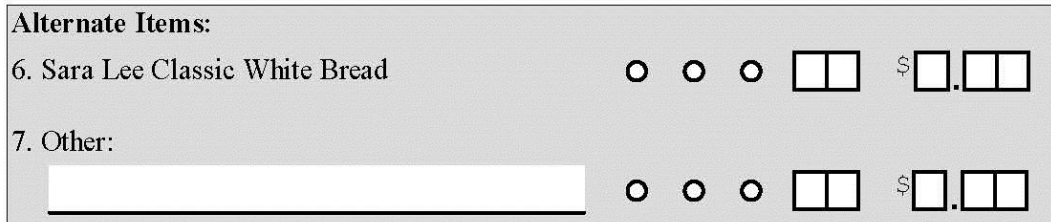




\section{Nutrition Environment Measures Survey (NEMS)} MEASURE \#10: CHIPS

Store ID:

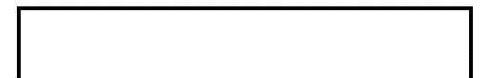

Rater ID:

Does this store sell chips?

Yes O No O

Comments:

If yes, continue. If no, move on to the next measure.

\section{Availability \& Price}

Low-fat chips $\leq 3 \mathrm{~g}$ fat $/ 1 \mathrm{oz}$. serving

\begin{tabular}{|llll|}
\hline Item & Size & Available & Price \\
\hline
\end{tabular}

Healthier Option :

Yes No

1. Baked Lays Potato Chips

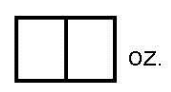

$\circ \circ$

$\$ \square . \square$

Alternate Item:

Yes No N/A

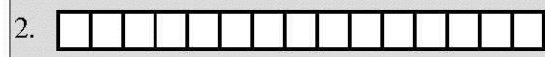

$\circ 00$

$\square . \square$

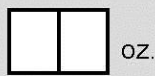

oz.

3. \# of varieties of low-fat chips (any brand)

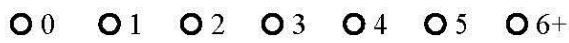

Regular Option (select most comparable size to healthier option available):

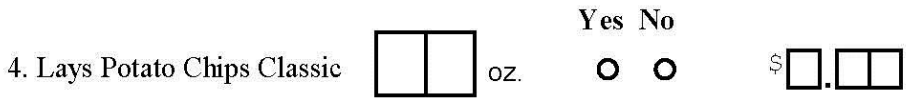

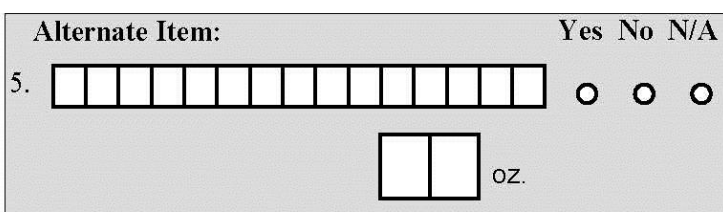




Nutrition Environment Measures Survey (NEMS)
MEASURE \#11: CEREAL

Store ID:

Rater ID:

Does this store sell any cereal? Yes $\mathrm{O}$ No $\mathrm{O}$

Comments:

If yes, continue. If no, move on to the next measure.

Availability \& Price

Healthier cereals $<7$ g sugar per serving

\begin{tabular}{|lllll|}
\hline Item & Available & Size & Price & Comments \\
& Yes No N/A & (ounces) & & \\
& & & \\
\hline
\end{tabular}

Healthier Option :

1. Cheerios (Plain)

$\circ \circ$

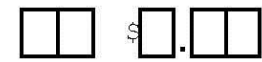

\begin{tabular}{l} 
Alternate Item: \\
2. Other \\
\hline
\end{tabular}

Yes No N/A

$000 \square \square \square \square$

3. \# of varieties of healthier cereals

$00 \quad 01 \quad 02 \quad 03$

Regular Option ( $>7 \mathrm{~g}$ of sugar per serving):

4. Cheerios (Flavored)

$\circ \circ$

$\square$ 口. प

\begin{tabular}{l} 
Alternate Item: \\
5. Other \\
\hline
\end{tabular}

Yes No N/A

O 0 ○ $\square \square \square . \square$ 